\title{
Concerns About Psychiatric Neurosurgery and How They Can Be Overcome: Recommendations for Responsible Research
}

\author{
Sabine Müller ${ }^{[} \cdot$ Ansel van Oosterhout $\cdot$ \\ Chris Bervoets • Markus Christen • \\ Roberto Martínez-Álvarez $\cdot$ Merlin Bittlinger
}

Received: 29 March 2021 / Accepted: 27 October 2021 / Published online: 7 February 2022

(C) The Author(s) 2022

\begin{abstract}
Background Psychiatric neurosurgery is experiencing a revival. Beside deep brain stimulation (DBS), several ablative neurosurgical procedures are currently in use. Each approach has a different profile of advantages and disadvantages. However, many psychiatrists, ethicists, and laypeople are sceptical about psychiatric neurosurgery.

Methods We identify the main concerns against psychiatric neurosurgery, and discuss the extent to which they are justified and how they might be overcome. We review the evidence for the effectiveness, efficacy and safety of each approach, and discuss how
\end{abstract}

S. Müller $(\bowtie) \cdot$ M. Bittlinger

Department of Psychiatry and Psychotherapy CCM, Mind and Brain Research, Charité - Universitätsmedizin Berlin, Berlin, Germany

e-mail: mueller.sabine@charite.de

A. van Oosterhout

Practice for Radiosurgery, Marien Hospital Düsseldorf,

Düsseldorf, Germany

C. Bervoets

University of Leuven, Universitair Centrum Voor

Obsessieve-Compulsieve Stoornissen, Leuven, Belgium

M. Christen

Institute of Biomedical Ethics and History of Medicine, University of Zurich, Zurich, Switzerland

R. Martínez-Álvarez

Hospital Ruber Internacional, Médico-Neurocirujano,

Madrid, Spain this could be improved. We analyse whether and, if so, how randomised controlled trials (RCTs) can be used in the different approaches, and what alternatives are available if conducting RCTs is impossible for practical or ethical reasons. Specifically, we analyse the problem of failed RCTs after promising open-label studies.

Results The main concerns are: (i) reservations based on historical psychosurgery, (ii) concerns about personality changes, (iii) concerns regarding localised interventions, and (iv) scepticism due to the lack of scientific evidence. Given the need for effective therapies for treatment-refractory psychiatric disorders and preliminary evidence for the effectiveness of psychiatric neurosurgery, further research is warranted and necessary. Since psychiatric neurosurgery has the potential to modify personality traits, it should be held to the highest ethical and scientific standards.

Conclusions Psychiatric neurosurgery procedures with preliminary evidence for efficacy and an acceptable risk-benefit profile include DBS and micro- or radiosurgical anterior capsulotomy for intractable obsessive-compulsive disorder. These methods may be considered for individual treatment attempts, but multicentre RCTs are necessary to provide reliable evidence.

Keywords Psychiatric neurosurgery · Deep brain stimulation · Gamma Knife - Capsulotomy · Cingulotomy $\cdot \mathrm{MRgFUS}$ 


\begin{tabular}{|c|c|}
\hline bbreviations & \\
\hline ALIC & Anterior limb of the internal capsule \\
\hline BDI & Beck's Depression Inventory \\
\hline $\mathrm{CT}$ & Computerised tomography \\
\hline DBS & Deep brain stimulation \\
\hline DGPPN & $\begin{array}{l}\text { Deutsche Gesellschaft für Psychi- } \\
\text { atrie und Psychotherapie, Psy- } \\
\text { chosomatik und Nervenheilkunde } \\
\text { e.V. (German Association for } \\
\text { Psychiatry, Psychotherapy and } \\
\text { Psychosomatics) }\end{array}$ \\
\hline DSM & $\begin{array}{l}\text { Diagnostic and Statistical Manual } \\
\text { of Mental Disorders }\end{array}$ \\
\hline EMA & European Medicines Agency \\
\hline FDA & Food and Drug Administration \\
\hline GAF & Global Assessment of Functioning \\
\hline GPi & Globus pallidus internus \\
\hline HAM-D & Hamilton Depression Rating Scale \\
\hline HDRS -17 or -28 & $\begin{array}{l}\text { Hamilton Depression Rating } \\
\text { Scale (with } 17 \text { or } 28 \text { items) }\end{array}$ \\
\hline HFS & High frequency stimulation \\
\hline ICD & $\begin{array}{l}\text { International Classification of } \\
\text { Diseases }\end{array}$ \\
\hline MADRS & $\begin{array}{l}\text { Montgomery-Asberg Depression } \\
\text { Rating Scale }\end{array}$ \\
\hline MDD & Major depressive disorder \\
\hline MRgFUS & $\begin{array}{l}\text { Magnetic resonance-guided } \\
\text { focused ultrasound }\end{array}$ \\
\hline MRI & Magnetic resonance imaging \\
\hline NAcc & Nucleus accumbens \\
\hline OCD & Obsessive-compulsive disorder \\
\hline QoL & Quality of life \\
\hline RCT & Randomized controlled trial \\
\hline SCC & Subcallosal cingulate cortex \\
\hline SCG & Subcallosal cingulate gyrus \\
\hline slMFB & $\begin{array}{l}\text { Superolateral branch of the medial } \\
\text { forebrain bundle }\end{array}$ \\
\hline STN & Nucleus subthalamicus \\
\hline VC/VS & Ventral capsule/ventral striatum \\
\hline WSSFN & $\begin{array}{l}\text { World Society for Stereotactic and } \\
\text { Functional Neurosurgery }\end{array}$ \\
\hline Y-BOCS & $\begin{array}{l}\text { Yale-Brown Obsessive-Compulsive } \\
\text { Scale }\end{array}$ \\
\hline
\end{tabular}

\section{Introduction}

Whereas medical ethicists have intensively discussed ethical questions around deep brain stimulation (DBS) for years, they have mostly neglected the widespread practice of ablative psychiatric neurosurgery. To address this blind spot, a comprehensive and differentiated ethical analysis of the pros and cons of distinct psychiatric neurosurgery approaches is needed, and this should be based on rational evidence rather than outdated prejudices. The international, interdisciplinary consortium "Psychiatric Neurosurgery - Ethical, Legal and Societal Issues" had been founded to address this issue. The consortium was tasked with investigating ethical, legal, and societal issues surrounding the field of contemporary psychiatric neurosurgery. ${ }^{1}$ The consortium consisted of researchers specialised in medical ethics, legal science, social science, neurosurgery, radiosurgery and psychiatry. Its members originate from Germany, Belgium, Spain, Switzerland, Canada, and the United States. The present paper has been elaborated by several members of the consortium.

Functional stereotactic neurosurgery was primarily developed and used to replace leucotomy; then it was extended into the treatment of pain, epilepsy and movement disorders [1]. Until the $1970 \mathrm{~s}$, neurosurgery for psychiatric disorders has been used in hundreds of thousands of patients with mental illness [2]- [5]. However, the morbidity and neurological sequelae of leukotomies became more and more evident, and patient selection criteria as well as the procedure's efficacy were questioned more critically [2]. Psychosurgery was nearly completely abandoned in the mid-1970s because of public criticism and because of the development of chlorpromazine and other antipsychotic drugs [5]. Psychosurgery remains forbidden in some countries, e.g., Japan [6]. Since the late $1990 \mathrm{~s}$, there has been a renaissance of psychiatric neurosurgery (i.e., neurosurgical treatments for psychiatric disorders $)^{2}$ [8]. This is because despite all the progress made in pharmacology and psychotherapy, a considerable number of patients still suffer from severe, possibly life-threatening medically refractory mental illnesses. For example, up to a third

\footnotetext{
${ }^{1}$ Further information (see also funding information): https:// mindandbrain.charite.de/en/projects/neurophilosophy_and_ ethics/psychiatric_neurosurgery/.

2 Psychiatric neurosurgery has the primary goal of improving symptoms of psychiatric diseases. Neurosurgical interventions intended primarily to improve motor functions, sensory functions, or an epileptic tendency may also improve cognitive or psychological functions, particularly in patients suffering
} 
of patients with major depressive disorder (MDD) can be classified as having treatment-resistant depression, and suicide rates in this patient population are approaching $15 \%$ [9]. Consequently, there is an urgent need for new and effective treatment methods.

DBS is an established, evidence-based therapy for treatment-refractory Parkinson's disease, ${ }^{3}$ essential tremor, and dystonia $[12,13]$. This fact as well as the adjustability of DBS and its high degree of reversibility $^{4}[16,17]$ are arguments for the experimental use of DBS for the treatment of severe treatment-refractory psychiatric disorders. Several recommendations for the ethical use of DBS have been published by teams of DBS experts and ethicists [18]- [23]. DBS

\footnotetext{
Footnote 2 (continued)

from neuropsychiatric diseases such as Parkinson's disease or epilepsy. However, these interventions are generally not considered as psychiatric neurosurgery. This use of the term is in line with the definition of psychosurgery from the National Commission for the Protection of Human Subjects from 1977, which stated: "Psychosurgery means brain surgery on (1) normal brain tissue [of an individual who does not suffer from any physical disease, for the purpose of changing or controlling the behavior or emotions of such individual] or (2) diseased brain tissue of an individual, if the primary object of the performance of such surgery is to control, change, or affect any behavioral or emotional disturbance of such individual. Under this wording, surgery with a dual purpose (e.g., relief of seizures, as well as relief of emotional disorders) falls within the definition of psychosurgery if the predominant reason for performing the operation is to affect the behavioral or emotional disturbance." [7] (page xvi).

3 The efficacy of DBS for Parkinson's disease is well established; in particular for outcome measures up to 36 months: motor benefits achieved with GPi and STN DBS for Parkinson disease are similar; DBS of STN allows for a greater reduction of medication, but does not have as significant an advantage as DBS of GPi with respect to mood [10]. Long-term studies indicate that STN DBS still improves motor function for up to 10 years, although the magnitude of improvement tends to decline over time. The incidence and severity of dementia among patients receiving DBS are comparable to those among patients who receive medical treatment. Severe adverse events are rare, but adverse events such as dysarthria are common and probably under-reported [11].

${ }^{4}$ DBS is widely described as reversible both in the medical literature as on patient information sides. However, this claim is false in some aspects and misleading in others [14]. Cellular changes surrounding the electrodes, the risk of intracranial hemorrhage during the implantation and the explantation of the electrodes, long-term changes in the brain as a result of chronic exposure to HFS [high frequency stimulation] have been described in the literature [14]. The insertion of the electrodes might cause irreversible lesions, even with the consequence of death or permanent neurological damage [8]. The reversibility of DBS is also questioned by many DBS experts:
}

for treatment-resistant obsessive-compulsive disorder (OCD) has Human Device Exemption approval in the United States, and CE mark ${ }^{5}$ in Europe [25]. Recently, the World Society for Stereotactic and Functional Neurosurgery (WSSFN) has stated that DBS in the ventral anterior capsule region (including bed nucleus of stria terminalis and nucleus accumbens) for otherwise treatment refractory OCD remains investigational; it represents an emerging, but not yet established therapy [23]. To meet the criteria of "standard of care", at least one additional, well-designed, blinded clinical trial is required [23].

Besides DBS, ablative neurosurgical procedures are also experiencing a revival in psychiatric neurosurgery. ${ }^{6}$ The ablative neurosurgical procedures currently in use include radiofrequency thermocoagulation, Gamma Knife or CyberKnife radiosurgery, and magnetic resonance-guided focused ultrasound (MRgFUS). A rough estimate of the publication activity in psychiatric neurosurgery in the last 10 years reveals a considerable increase in the number of publications in psychiatric neurosurgery compared to DBS (Fig. 1). Furthermore, a survey of DBS experts showed that more than two-thirds believe that lesional procedures are a valid alternative to DBS [15]. According to a recent survey with members of the American Society for Stereotactic and Functional Neurosurgery, even $87 \%$ of all respondents agreed with this statement [36]. An expert panel has affirmed that ablative procedures are important options for appropriately selected patients [21]. The high acceptance of lesional procedures within the community of stereotactic and functional neurosurgeons and even among DBS researchers stands in stark contrast to the lack of interest for these procedures in medical ethics.

PubMed search (start date: 01.01.2000, end date: 31.12.2020; search performed on September 3, 2021).

Footnote 4 (continued)

Our expert survey showed that about $40 \%$ of the participating DBS experts (strongly) disagree with the statement that DBS is a completely reversible procedure, whereas $43 \%$ (strongly) agree [15].

${ }^{5}$ The letters 'CE' appear on many products traded on the extended Single Market in the European Economic Area (EEA). They signify that products sold in the EEA have been assessed to meet high safety, health, and environmental protection requirements [24].

${ }^{6}$ For detailed descriptions of the different approaches and their mechanisms of action, we recommend the textbooks [4], [26], [27], and the papers [2], [4], [12], [16], [17], [28]- [35]. 
Fig. 1 Publication activity in psychiatric neurosurgery from 2000 to 2020

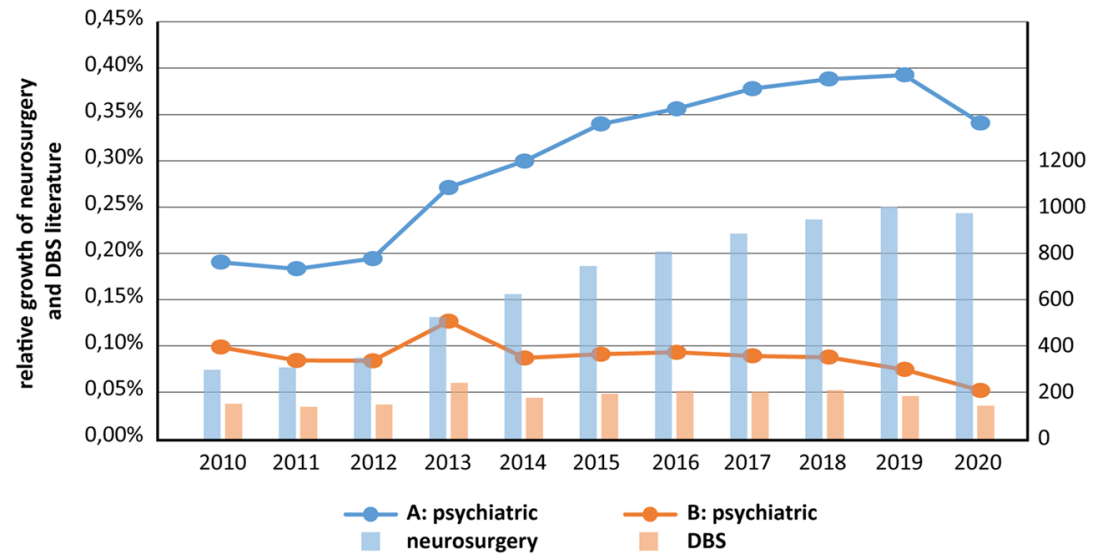

Search terms: (A) (mental disorder[MeSH Terms]) AND (neurosurgery); (B) (mental disorder[MeSH Terms]) AND (“deep brain stimulation”). To ensure that the depicted trends do not just reflect overall growth of the neuroscientific literature, the absolute numbers of publications per year ( $y$-axis on the right side) have been normalized with the overall neuroscience publication activity per year using a validated keyword set (neuro* OR neural OR brain* OR amygdala OR cerebellum OR cortical OR cortex OR hippocampus; see [37]). The left y-axis shows the relative growth per year for the sets A and B.

Modern psychiatric neurosurgery procedures are much safer and more effective than their predecessors $[2,38]$. Therefore, it is necessary to re-evaluate the role of historical experiences with psychiatric neurosurgery in assessing the modern use of these techniques. Furthermore, the present distinction between modern ablative procedures as successors of historical psychosurgery and DBS as a substantially different approach needs to be questioned, as both psychiatric DBS and modern ablative psychiatric neurosurgery represent significantly improved successors of the historical psychosurgery [8, 39]. Furthermore, DBS target selection is largely based on prior knowledge about lesioning [2].

From a clinical perspective, evidence indicates that each of these approaches has a different profile of advantages and disadvantages such that no procedure can be considered absolutely superior to another [2, 8, 38, 40]- [43]. Specifically, DBS is advantageous for its adjustability and a high degree of reversibility [16, 17], whereas radiofrequency thermocoagulation has a rapid onset of action, and radiosurgery and MRgFUS are minimally invasive and have low rates of adverse effects [8, 41]. All ablative procedures share the advantage of the permanence of the therapeutic effect and, accordingly, the disadvantage of the irreversibility of potential adverse effects. Radiofrequency thermocoagulation and radiosurgery have higher response rates for OCD and less adverse effects than DBS [40, 42]. Radiofrequency thermocoagulation and DBS have the drawback that they require full anaesthesia. Gamma Knife radiosurgery has the disadvantage of the use of radiation and the latency of the therapeutic effect [35]. DBS has the drawback of being very costly [2, $40,44,45]^{7}$ and time-consuming for patients, limiting their geographical mobility, and having high risks

${ }^{7}$ For Medicare reimbursements, the following professional and facility costs can be expected:

- DBS: $\$ 43,127$ (in case of major perioperative complica tions: $\$ 52,288$ ) plus $\$ 22,591$ for 5 years of follow-up includ ing device exchange (in case of complications: \$3,764).

- Radiofrequency thermocoagulation: $\$ 23,950$ (in case of major perioperative complications: $\$ 34,651)$.

- Gamma Knife ${ }^{\circledR}$ radiosurgery: $\$ 17,104$ (additional costs for major complications: \$31,621).

- MRgFUS: \$17,660 (additional costs for major complications: $\$ 31,621)$.

Information on the cost of Gamma Knife ${ }^{\circledR}$ and DBS was taken from [44], information on radiofrequency capsulotomy and MRgFUS from [46]. Although the first paper is about essential tremor and the second is about OCD, the costs are similar because the procedures are very similar. Furthermore, the same team has produced both papers using the same methods. The costs for 5 years of follow-up (including battery change) were taken from [45]. These numbers refer to DBS treatment for Parkinson's disease. 
of infection, complications, and device malfunction $[8,25]$. MRgFUS has the disadvantage of requiring a complete shaving of the skull [34]. Furthermore, the different approaches each have different contraindications. DBS and radiofrequency thermocoagulation should not be used for patients with higher risks of full anaesthesia and for patients using anticoagulant therapy; furthermore, DBS should not be used for patients with higher infection risks, patients who would not comply with long-term follow-up, and for patients with behaviours such as head-banging. MRgFUS must not be used for patients with high skull density ratio $(>0.45)$ or structural abnormality in proximity to the anterior limbs of the internal capsule (ALICs) [29].

Overall, 20years of psychiatric DBS and several decades of ablative psychiatric neurosurgery have resulted in a mixed picture of risk and benefits. It is difficult to compare the risk-benefit ratios of the different methods, particularly because they have not yet been compared directly.

According to an international survey of functional neurosurgeons, $90 \%$ felt optimistic about the future of psychiatric neurosurgery [47]. Nearly all respondents of a survey among members of the American Society for Stereotactic and Functional Neurosurgery perceived the reluctance of psychiatrists to refer as a barrier for psychiatric neurosurgery [36]. In contrast, many psychiatrists are not interested in psychiatric neurosurgery or even strongly reject it. According to a survey of psychiatrists and psychiatric residents on their attitudes and knowledge about psychiatric neurosurgery, a third of psychiatrists and psychiatric residents consider psychiatric neurosurgery dangerous [48]. However, respondents were significantly more likely to refer patients to DBS than to ablative neurosurgery [48]. Psychiatrists have many barriers to patient referral, including a lack of knowledge, administrative limitations, fear of irreversible consequences, and patient/family resistance [48]. For these reasons DBS trials face challenges recruiting a sufficient number of patients [12]. Thus, a vicious circle is created in that skepticism leads to low patient numbers in psychiatric neurosurgery studies, which thus have insufficient power, which in turn is reason for justified skepticism.

Many bioethicists and laypeople are sceptical of psychiatric neurosurgery as well [49]- [52].
Given the difficulty of making a comparative assessment of methods in psychiatric neurosurgery and given differing views among neurosurgeons, psychiatrists, ethicists, and laypeople it is necessary to thoroughly investigate the concerns over psychiatric neurosurgery and the extent to which these concerns are justified.

Further research in psychiatric neurosurgery is warranted because of the preliminary evidence for its efficacy and in light of the urgent need for effective therapies for treatment-refractory psychiatric disorders. However, neither the high mortality rates of severe psychiatric disorders nor their socioeconomic burden can justify therapeutic adventurism. Since psychiatric neurosurgery has the potential to modify some personality traits and the behaviour of patients, these interventions must meet the highest ethical and scientific standards.

Therefore, in the next section, we discuss the main concerns around psychiatric neurosurgery and suggest several measures to ensure that psychiatric neurosurgery research proceeds in accordance with the highest scientific and ethical demands.

\section{Concerns About Psychiatric Neurosurgery}

\section{Concern: Modern Psychiatric Neurosurgery As a Successor of Lobotomy}

The historic misuse of psychosurgery is one of the most important barriers for psychiatric neurosurgery according to a survey among members of the American Society for Stereotactic and Functional Neurosurgery [36].

The stigma of historical psychosurgery almost exclusively pertains to ablative procedures [2, 49, 50], perhaps because the advocates of DBS have successfully redefined this neurosurgical approach as a stimulation or neuromodulation technique.

Popular media reports have been relatively positive and optimistic about DBS, but negative toward both historical and modern ablative psychiatric neurosurgery procedures [50]. Furthermore, many laypeople consider modern psychiatric neurosurgery, particularly ablative procedures, as a contemporary successor of lobotomies [49]. 
Also, the German Association for Psychiatry, Psychotherapy and Psychosomatics (DGPPN) connects ablative procedures - but not DBS - with the "very controversial history of neurolesional or ablative methods" [53] (p. 83). ${ }^{8}$ By contrast, the Royal College of Psychiatrists emphasises that "contemporary stereotactic neurosurgical procedures - whether stereotactic lesioning, or deep brain stimulation - bear no resemblance to those of lobotomy or leucotomy" [56].

Concerns over modern psychiatric neurosurgery as a successor of lobotomy and leucotomy are not justified given the considerable differences between these historical and the modern techniques. The use of stereotactic surgery, advances in neurosurgery and the use of neuroimaging have greatly improved the accuracy and specificity of targeting. Together with an improved understanding of neurobiology, this has significantly improved the safety and efficacy of both DBS and ablative procedures [2, 38].

Due to the fundamental differences between modern and historical techniques, the condemnation of psychiatric neurosurgery based on its historical predecessors is not justified. Generally, it is not ethically justifiable to determine the admissibility of medical therapies based on their history rather than on scientific evidence; otherwise, patients may be denied good therapies [57].

\section{Concern: Personality Changes Through Psy- chiatric Neurosurgery}

Some people hold concerns about the potential impact on the authentic self of patients who undergo psychiatric neurosurgery [52]. Some fear the possibility of mind control by technical devices in the brain. This fear mainly concerns DBS, which, unlike ablative neurosurgery, makes patients susceptible to ongoing influences [51].

\footnotetext{
8 The DGPPN guideline on the treatment of OCD [53] does not consider any recent publications, summarizing only a review of studies from the 1970s [54] and one Gamma Knife study that used excessively high radiation doses [55]. Consequently, the authors reject ablative methods without further ado, whereas they make a cautious recommendation for DBS without associating it with the historical psychosurgery [53] (pp. 82-84).
}

Many OCD patients as well as many psychotherapists have concerns about DBS-induced personality changes [58].

The main concern of philosophers and medical ethicists is that psychiatric neurosurgery threatens the patients" "personal identity" or "true self," and could change their personality or even transform them into a "different person" [51]. However, this philosophical criticism is more metaphysical than empirically supported and exaggerates the risk of personality change following psychiatric neurosurgery, as we $[59,60]$ and others $[61,62]$ have shown. This criticism could contribute to unfounded fear in the public, and inappropriately discourage patients from seeking out potential treatments [62]. Furthermore, it has been used for problematic ethical and legal conclusions such as the denial of Ulysses contracts ${ }^{9}$ [60]. The concern about the threat of the personal identity seems to be based on a static concept of personality or on the idea of the sanctity of the personality. However, personality is not stable over a person's lifetime anyway. Indeed, personality is constantly altered by experiences and by psychiatric or neurological diseases such as depression or dementia. Effective treatments for severe psychiatric disorders might arguably restore the patient's personality.

Therefore, the ethically decisive question is not whether psychiatric neurosurgery can change the personality or not [63]- [65], but whether it does so in a good or bad way, i.e., first whether the result of change is good or bad ${ }^{10}$; second whether the way of change is good or bad [59] (p. 105). Consequently, personality changes through interventions in the brain can be considered as ethically problematic if they (i) occur against the patient's will, (ii) harm either the patient or third persons, (iii) reduce the patient's capacity for autonomy, or

\footnotetext{
${ }^{9}$ Ulysses contracts can be used to determine in a legally binding manner what measures doctors should take in the event of psychosis or mania, if necessary, against one's own will, in order to restore one's capacity for insight and control and to avert serious consequences of a pathological or iatrogenic change of will.

10 Of course, the evaluation of personality changes strongly depends on culture, ideology and on individual evaluations [64], [66].
} 
(iv) diminish valuable abilities. ${ }^{11}$ Whereas negative personality changes should be avoided, positive personality changes should be accepted or even encouraged, regardless of whether they are of natural or surgical origin.

Whether personality changes will occur as a result of psychosurgery at all has been the subject of controversy since the 1960 s [68]. On the one side, personality change as a result of psychosurgery has been commonly offered as the rationale for its effectiveness; on the other side, it was denied that improvement in mood meant a change in personality [68]. Bouckoms concludes that "true personality traits", particularly the attitude to morality, sex, religion and family, are not changed [68]. In contrast to the medico-ethical literature, in the medical literature about psychiatric neurosurgery, the term "personality change" is rather unusual. Systematic comparisons of the pre- and post-personality of patients (e.g., in terms of the "Big Five"12) are very rare. One example is a Gamma Knife capsulotomy study with OCD patients which found that the responders showed a significant reduction in neuroticism and an increase in extraversion; this pattern of personality change was generally towards normal personalities, and no deleterious effects on personality were observed [70].

Information about personality changes can sometimes be found in sections about permanent

\footnotetext{
11 These conditions are derived partly from Beauchamp and Childress' principles [67], partly from Müller's refinement of the principles with regard to neurosurgical interventions, which could change the personality or the capability for autonomy [59] (pp. 91-106). The first condition (occur against the patient's will) clearly violates the principle of respect for the patients' autonomy. According to Müller, also the third condition (reduce the patient's capacity for autonomy) violates this principle because it does not only mean to respect existing autonomy, but beyond that, to save or restore the biological and social prerequisites of autonomy if they are endangered [59] (p. 98). The first part of the second condition (harm the patient) obviously violates the principle of non-maleficence, whereas its second part (harm third persons) violates this principle only, if it is expanded to third persons, who are indirectly concerned by a given intervention [59] (p. 104). Interventions which might harm indirectly third persons might also violate the principle of justice [59] (p. 104). The fourth condition (diminish valuable abilities) obviously violates the principle of non-maleficence.

12 The "Big Five" are the basic personality traits, namely extraversion, neuroticism, agreeableness, conscientiousness, and openness to experience [69].
}

adverse effects. Reported are especially cases of aggression, disinhibition, hypomania, hypersexuality, impulsivity, and agitation after DBS [71, 72]. After lesional procedures, apathy, disinhibition, hypersexuality, impulsivity or agitation have occurred [55, 71].

Several reviews and medico-ethical papers summarize information from studies and case reports about personality changes after different neurosurgical interventions for neurological and/or psychiatric disorders, e.g., [64, 66, 71, 73]- [76]. For all treatment options, the spectrum of personality changes is heterogeneous; positive as well as negative changes are reported. However, permanent negative changes are rare.

Particularly important for understanding the spectrum of personality changes are the few interview studies with patients and/or their caregivers, e.g., $[72,77,78]$. They provide deeper insight into the patients' experiences with personality change than studies with standard psychometric personality measures [72].

Some patients have reported impressively in autobiographical books how they recovered from severe OCD after Gamma Knife capsulotomy [79, 80].

Whereas some DBS patients experience the "restoration of their old self" [72] or perceive themselves as "a new and improved version" of themselves [81], others feel "dehumanized " [72].

Altogether, the scientific knowledge about personality changes after psychiatric neurosurgery is more anecdotic than comprehensive and systematic. One reason for that is the conspicuous lack of instruments which target and adequately depict personality-related changes following psychiatric neurosurgery [82]. Another reason is that no study to date has directly compared DBS and ablative surgery [71]. Therefore, not much is known about the different frequency of personality changes after the different neurosurgical interventions.

Instead of metaphysical discussions about threats to the personal identity, we plead for a pragmatic approach: empirical research on personality changes arising from brain disorders or the different kinds of psychiatric neurosurgery, and comprehensive information about risks of personality changes. 


\section{Concern: Localised Interventions Instead of Holistic Ones}

Other concerns centre on the use of localised interventions into the brain, under the assumption that only a holistic approach can be successful to treat psychiatric disorders.

However, this critique is partly based on a misunderstanding of how psychiatric neurosurgery works. Psychiatric neurosurgery is more than a localised intervention. The localised stimulation or ablation influences large networks of neurons and therefore can have whole brain-wide effects [13]. For example, neuroimaging studies suggest that overactivity of cortico-striatal-thalamocortical circuits plays a role in OCD [25, 32]. On these grounds, psychiatric neurosurgery that intervenes in these circuits can be regarded as just as holistic a brain therapy as psychopharmacology.

However, the brain-based concept of psychiatric neurosurgery is diametrically opposed to the approach of psychotherapy and to a psychosocial understanding of psychiatric disorders. Therefore, no common therapeutic tradition exists, and it is difficult to imagine how the gap between these two therapeutic cultures could be bridged.

\section{Concern: Lack of Scientific Evidence of Psy- chiatric Neurosurgery}

Finally, many psychiatrists and patients are sceptical of psychiatric neurosurgery because it lacks scientific evidence for its efficacy and safety. In a study with patients suffering from treatment-resistant depression, the majority said they would not try DBS until large controlled clinical studies had been performed, and many would wait for robust trials showing excellent results [83]. The potential for adverse effects is the most ubiquitous barrier for patients and clinicians when considering psychiatric neurosurgery according to a survey among members of the American Society for Stereotactic and Functional Neurosurgery [36]. The concern about adverse effects, particularly about surgeryrelated complications, was frequently expressed by patients suffering from treatment-resistant depression [83] or OCD [58], as well as by psychiatrists and psychotherapists [58].

The concern about scientific evidence for the efficacy and safety is the most important one, and we will therefore consider it in detail. Indeed, most of the studies in psychiatric neurosurgery do not meet the basic scientific criteria that are standard in pharmaceutical research. In particular, most studies of psychiatric neurosurgery procedures are neither sham-controlled nor double-blind, and few studies have adequate statistical power. No pharmaceutical researcher would accept these studies as sufficient evidence in favour of the intervention.

On the other side, neurosurgeons who use ablative procedures are convinced that a multitude of openlabel studies and many years of practical experience have sufficiently proven the efficacy of psychiatric neurosurgery procedures [2]. Randomised controlled trials (RCTs) with ablative procedures versus sham operation are ethically problematic because of the high level of risk and harm of neurosurgical interventions which is not balanced by any clinical benefit. ${ }^{13}$

Obviously, the cultures of research in psychiatry and neurosurgery differ from one another. For psychiatric neurosurgery to be accepted by psychiatrists, the crucial question is this: How can psychiatric neurosurgery research meet the criteria of evidence-based medicine despite practical and ethical limitations? There is general agreement that invasive, burdensome, and risky procedures - which are also associated with enormous costs - should not be introduced into clinical practice without good scientific evidence. Therefore, the effectiveness, efficiency, and spectrum and rate of adverse effects for each new treatment method must be investigated carefully before it is broadly used.

The gold standard of evidence-based medicine is the RCT, a trial designed to exclude placebo or doctor effects. However, RCT ideal can be perfectly met only in experiments with genetically identical animals raised under identical conditions. In most human studies, different forms of bias occur [85]. To compensate for such bias, studies require either a high number

\footnotetext{
13 The ethical arguments against sham surgery have been discussed controversially in the last decade [84]. Although there is no absolute ban against sham surgery in neurosurgery anymore, sham operations with craniotomy in patients suffering from severe psychiatric disorders do not fulfill the requirements of the ethical assessment as defined by Horng and Miller [84] because of the high level of risk and the often-affected decision-making capacity of the patients.
} 
of participants or extensive statistical work. In psychiatric neurosurgery, high numbers of study participants cannot be realized because the pool of potential surgical candidates is extremely small. $^{14}$

RCTs are especially important in the following cases: (i) if the symptoms often respond to a placebo or to a doctor's special attention (e.g., depressive mood, pain, nausea); (ii) if the symptoms are mainly subjective and the ability to measure them by objective methods is limited (e.g., depressive mood or pain); (iii) if the treatment bears a large potential for placebo effects (e.g., invasive treatments, expensive treatments, high-tech treatments, treatments hyped in the mass media, or treatments with augmented patient-practitioner interactions) [87]; (iv) if the effect will occur only after a long waiting period, in which many other factors can influence the outcome (e.g., psychoanalytical therapy); or (v) if the symptoms may resolve without treatment (e.g., depressive episodes).

RCTs are less important when the symptoms for the disorder in question do not respond to placebo treatments (e.g., blindness or deafness) or can be measured objectively (e.g., seizures, dystonia) or if the effect of the treatment in question occurs quickly (e.g., decline of pneumonia after antibiosis) or can be switched on and off (e.g., hearing with cochlear implant). ${ }^{15}$

An RCT investigating a treatment with a large intrinsic placebo effect generally requires more participants than a treatment with a smaller placebo effect [87]. This might explain why some treatment methods with promising initial openlabel, single arm studies have mixed results in subsequent (underpowered) RCTs [87]. In some cases, the "efficacy paradox" occurs [87], leading

\footnotetext{
$\overline{14}$ In the USA, only 4,020 OCD patients in total (or 184 OCD patients per year) are considered good candidates for psychiatric neurosurgery [86].

15 For example, if a patient with monocular blindness is able to see again binocularly after the surgical removal of a brain tumor that had comprised the visual nerve, the success of the intervention has been undoubtably proven. However, if 6 months after DBS the cognitive decline of an Alzheimer's patient is minimally smaller than the average cognitive decline of a group of Alzheimer's patients, it is still questionable whether the effect has been caused by DBS or by something else that happened during the 6-month period.
}

to a faulty evaluation of methods that have a large effect, but also a large placebo effect. ${ }^{16}$ In such cases, it is worth investigating the placebo effect more closely.

RCTs are also important for differentiating between two different effects of a single treatment, e.g., the lesion effect and the stimulation effect of DBS. Trials with sham stimulation are ethically permissible for investigating the stimulation effects. However, sham operations without electrode insertion are not ethically permissible; therefore, it is not possible to differentiate between the lesion effect of DBS and the placebo effect. Regarding the lesion effect, DBS studies have the same limitations as ablative neurosurgery studies. However, RCTs are not the only study designs that can produce valuable scientific evidence. If a treatment cannot be tested in an RCT for practical or ethical reasons, other strategies are available. In particular, head-to-head comparisons and pre- and post-treatment comparisons of a sufficient number of patients can prove the efficacy of a method and document its spectrum and rate of adverse effects. Another possibility is an n-of- 1 trial [88, 89], insofar as it is ethically justifiable.

An evidence-based comparison of different psychiatric neurosurgery procedures is necessary. To date, it has not been possible to prove the superiority of one particular approach in terms of efficacy, efficiency, risks, adverse effects, costs, and patient acceptance.

\section{General Recommendations for Research in Psychiatric Neurosurgery}

\section{Cooperation and Competition}

We argue for both cooperation and competition between the different psychiatric neurosurgery approaches.

\footnotetext{
${ }^{16}$ Burke et al. explain the differential placebo effects paradigm through the following hypothetical trial: Drug A and Device B are tested as treatments for the same condition. Drug A is compared with an inert pill, Device B with a sham device. Drug A has a moderate treatment-specific effect with a small placebo effect, whereas Device B has a large placebo effect and a smaller treatment-specific effect. However, the overall effect of Device B is larger than that of Drug A. Statistical significance is found for the trial of Drug A, but not for Device B. Therefore, Device B would not be considered efficacious. However, with regard to the overall treatment effect, Device B is superior to Drug A. This is the "efficacy paradox" [87].
} 
Some medical centres offer both DBS and neuroablation, thereby guaranteeing cooperation and competition. We are convinced that the different approaches can mutually support one another's future development. In the long-run, DBS could become the preferable method for exploring new targets because of its high degree of reversibility, whereas well-established targets could become candidates for radiofrequency thermocoagulation, radiosurgery, or MRgFUS [41].

A direct comparison of all psychiatric neurosurgery approaches would be optimal. However, the scientific standard of randomised, sham-controlled, and double-blind experiments comparing all approaches cannot be conducted for practical and ethical reasons. ${ }^{17}$ To compensate for this limitation, we recommend investigating the different procedures separately, but using the same inclusion criteria, outcome parameters, and criteria for reporting adverse effects. Furthermore, we recommend performing clinical studies that directly compare two or more alternative neurosurgical treatments.

\section{Individual Treatment Attempts With Procedures With Preliminary Evidence}

There is a major difference between research studies of a neurosurgical method and individual treatment attempts with that method, for which only some preliminary evidence exists.

Article 37 of the Declaration of Helsinki [90], in addition to the laws of many countries, allow individual treatment attempts of certain therapies and procedures under certain circumstances. However,

\footnotetext{
17 A randomization of patients to radiofrequency thermocoagulation, radiosurgery, MRgFUS or DBS is not possible, because it has to be expected that most patients have strong preferences for a certain approach and would not accept to be treated with an approach which they refuse. This would cause a strong bias due to a high number of patients rejecting their participation after randomization. Furthermore, it is impossible to blind the patients with regard to the therapy received. Even if all patients would receive full anaesthesia, they could easily find out whether they had been treated with Gamma Knife, MRgFUS, radiofrequency thermocoagulation or DBS. From an ethical point of view, it is not acceptable to treat all patients with full anaesthesia only for blinding them, because full anaesthesia is not necessary for radiosurgery, and would be an additional risk. Finally, shame operations in the skull would harm the patients severely; therefore, they are ethically not acceptable.
}

undergoing an individual treatment attempt typically requires that the treatment in question be FDA- or EMA-approved for another relevant medical indication (i.e., "off-label"). However, many psychiatric neurosurgery interventions are not yet approved by regulatory authorities for the treatment of psychiatric symptoms. In Germany, such treatments can only be seen as "compassionate use," if the condition is lifethreatening and clinical trials are to be conducted [91].

For many applications (e.g., new DBS or lesion targets), some evidence for beneficial effects exists, but it is preliminary because the studies did not have a control group or involved too few participants. In these cases, we recommend further investigating these applications in hypothesis-driven clinical trials with enough statistical power and, if ethically justifiable and technically feasible, in double-blind controlled studies. This strategy requires cooperation between multiple centres in order to enrol a sufficient number of patients.

\section{Comprehensive Investigation of Treatment-resistance}

An important inclusion criterion for studies of psychiatric neurosurgery procedures is usually that the patient is treatment-resistant. Treatment-resistance is typically diagnosed when a patient has not responded to a certain number of psychopharmacological and psychotherapeutic treatments, possibly including electroconvulsive therapy [86]. However, this criterion is problematic for two reasons.

First, we have found several studies, especially studies with anorexia nervosa patients, in which treatment-resistance was questionable, because most patients either had been ill for less than two years or had not received all standard therapies [74].

Second, even if the standard criteria for treatment resistance are fulfilled, it is possible that the patient is treatment-resistant to psychiatric drugs, but not to all kinds of drugs. Many case reports and several clinical studies document how seemingly treatment-resistant psychiatric patients were healed by anti-inflammatory drugs [92]- [94], plasma exchange and/or immunotherapy [95, 96], antibiotics [97], or a gluten-free diet [98].

Before an intervention as invasive as psychiatric neurosurgery should be considered, all potentially causal therapies should be tried, firstly, because they might fix the disorder permanently instead of just curing symptoms, secondly, because they are usually 
less invasive and dangerous. Therefore, we recommend that patients with mental illness undergo comprehensive somatic and neurological investigation to determine possible somatic causes of a psychiatric disorder, no matter how unlikely they may be. In particular, autoimmune diseases, infectious diseases (including neglected tropical diseases), hormonal disturbances, food intolerances (e.g., celiac disease), malnutrition (e.g., vitamin $\mathrm{B}_{6}, \mathrm{~B}_{12}$, or $\mathrm{D}$ deficiencies, etc.), and parasite infections should be assessed as potential causes of the mental disorder.

Furthermore, patients whose psychiatric symptoms are caused and maintained by their social circumstances should not be treated with psychiatric neurosurgery. In these cases, the social situation should first be improved.

\section{Inclusion of Patients Into Studies Based on Disease Causes Instead of DSM or ICD Diagnoses}

Biologically orientated psychiatry views psychiatric disorders not as disease entities but rather as clusters of symptoms which may have quite different aetiologies and require quite different treatments. From this perspective, it does not make sense to treat psychiatric disorders caused by social exclusion, mobbing, or loneliness with the same therapy as psychiatric disorders caused by viral or bacterial infections, metabolic disorders, chronic pain disorders, hormonal disturbances, or brain diseases.

Furthermore, it does not make sense to treat, for example, all anorexia nervosa patients in the same way, regardless of whether their symptoms are characterised more by anxiety, depression, or OCD. Therefore, we recommend the treatment of symptoms rather than diagnoses; in other words, targets for lesioning or stimulation should be selected on grounds of an individual patient's key symptoms instead of DSM or ICD diagnoses [74]. For example, for each individual anorexia nervosa patient the target should be selected according to whether OCD or depressive symptoms dominate.

Case Registries, Obligation to Publish, and Long-term Follow-up Studies

The demand for case registries is not new. As early as 1977, a registry was recommended in a report on psychosurgery by the U.S. National Commission for the Protection of Human Subjects of Biomedical and Behavioral Research [7]. With regard to DBS, Schläpfer and Fins demanded that all single case studies be registered in a comprehensive registry of initiated clinical studies [99]. They warned that publication bias leads to a distortion of available evidence, and this can harm patients, who might undergo procedures that might not be justified if all data were available. Furthermore, publication bias leads to unneeded clinical studies and squandering of resources. A national or international case registry would also serve to further inform candidate selection and optimize patient outcomes for the very unique pool of psychiatric neurosurgery patients [86].

An international expert group has recommended an independent registry for all patients undergoing neurosurgery for psychiatric disorders [21]; however, such a registry has not yet been established.

We also strongly recommend the registration not only of all clinical studies, but also of all individual treatment attempts in psychiatric neurosurgery. For each patient, the registry should contain psychiatric scores, data on quality of life and social functioning, and preand post-operative data including all adverse effects. The registry should be publicly available so that all researchers and patient organisations can use the information. The scientific evaluation of the registry could contribute to evidence-based answers to questions regarding personality changes. For example, the data analysis could reveal which biological, interventionspecific, and psychosocial factors influence whether personality changes occur, whether they are permanent, and how patients evaluate them. Information on the status of ongoing studies and their results should be published in the registry on agreed dates. Sanctions should be imposed for non-compliance, e.g., the exclusion of the institution concerned from public funding for a certain period of time.

Publication bias and selective reporting are a known issue in biomedical research [100], and neurosurgical research is not immune to this [101]. Fewer than half of U.S. clinical trials have complied with the law on reporting results [102]. Similarly, academic research in Germany also has low rates of result reporting [103].

We recommend that funding organisations stipulate that the results of the studies must be published - even on the institution's homepage if necessary (i.e., if no serious journal wants to publish them). Another option 
is so-called pre-print archives (bioRxiv, medRxiv, osf. io) that publish results without peer-review and assign a Digital Object Identifier (DOI) that can be cited by other scientific publications. Within 12 months, results from completed clinical research should be published on ClinicalTrials.gov or EUdraCT.

Furthermore, long-term prospective follow-up studies of psychiatric neurosurgery are necessary. Research and clinical protocols should include support for longterm safety and efficacy studies on psychiatric neurosurgery with at least 5-10years of follow-up [21].

With these measures, two problems that undermine the credibility of psychiatric neurosurgery could be overcome: first, the problem of too few cases, and second, the problem of publication bias.

\section{Recommendations for Research on Different Psychiatric Neurosurgery Approaches}

In the following paragraphs, we summarize the current state of knowledge for the different psychiatric neurosurgery procedures and formulate concrete recommendations based thereon.

\section{Recommendations for Radiofrequency}

Thermocoagulation

Several prospective open-label studies with individual pre- and post-surgery comparisons have been performed; these consistently show large effect sizes in a relevant number of patients.

A review by Pepper et al. of radiofrequency anterior capsulotomy studies for OCD found that $79 \%$ of patients (i.e., 125 of 158) had a clinically significant response $^{18}$ (publications from 2002 to 2018) [43].

A systematic review by Brown et al. compared dorsal anterior cingulotomy for OCD (2 studies, 81 patients) with anterior capsulotomy (8 studies, 112 patients) [28]. The mean reduction in Y-BOCS score was $37 \%$ for cingulotomy and $57 \%$ for capsulotomy. The average full response rate to cingulotomy was $41 \%$ and $54 \%$ to capsulotomy. The rate of serious or permanent adverse effects was higher for capsulotomy than for cingulotomy (21.4\% vs 5.2\%) [28].

\footnotetext{
${ }^{18}$ In the OCD studies, response is defined as a $>35 \%$ improvement in Y-BOCS score and remission is defined as a Y-BOCS score $<8$.
}

Pepper et al. compared microsurgical and radiosurgical anterior capsulotomy studies with DBS studies (in the VC/VS or NAcc) for OCD. They determined that anterior capsulotomy was superior (average response rate: anterior capsulotomy: $62 \%$; DBS: $52 \%$ ) [42].

A systematic meta-analytic study compared outcomes of neuroablation (radiofrequency thermocoagulation and radiosurgery) versus DBS for OCD with regard to both safety and utility [40]. Data from 56 studies (involving 681 patients) were included. The pooled ability to reduce Y-BOCS scores was $50.4 \%$ $( \pm 22.7 \%)$ for neuroablation and $40.9 \%( \pm 13.7 \%)$ for DBS. Adverse effects occurred in $43.6 \%( \pm 4.2 \%)$ of neuroablation cases and $64.6 \%( \pm 4.1 \%)$ of DBS cases $(\mathrm{p}<0.001)$. Overall, neuroablation was superior to DBS in its cumulative overall effect on utility [40].

The most recent meta-analysis compared capsulotomy and cingulotomy (microsurgery and radiosurgery) with DBS for OCD [71]. Data from 38 studies (697 patients) were included. DBS and ablative surgery showed equal efficacy. A statistically higher rate of impulsivity and a trend toward a statistically significant higher rate of (hypo)mania were reported after DBS than after capsulotomy [71].

A review by Volpini et al. reported that $30-60 \%$ of patients benefited from radiofrequency thermocoagulation for MDD [35].

In a retrospective study with 10 patients with autism spectrum disorder, severe (self)aggressiveness and obsessive behaviors, radiofrequency treatment and/or Gamma Knife radiosurgery led to a significant symptom improvement in all patients [104]. Complications were transient and manageable, and the cognitive and neurological situation of the patients did not worsen after the interventions [104].

None of these studies were RCTs. However, ethics committees would not allow sham-controlled, double-blind radiofrequency thermocoagulation studies, and it would be unrealistic to demand them. However, further efforts should be undertaken to exclude possible placebo effects in psychiatric neurosurgery studies. We recommend head-to-head comparisons between a group that undergoes surgery and a control group (e.g., patients on the waiting list), wherein the patients and controls are matched 1:1 for symptom severity, age, and gender. Such a study has been performed with five patients who underwent anterior capsulotomy and five control patients. Both groups 
received the same pharmacological and psychotherapeutic treatment. The reduction of Y-BOCS was significantly larger in the operated group [105].

Additionally, we recommend studies that involve direct comparisons of different surgical approaches, e.g., capsulotomy and cingulotomy, or different lesion characteristics in RCTs. As long as there is clinical equipoise, such studies are ethically justifiable. If the efficacy between the two approaches differs significantly, this would be a strong argument against the suggestion that neuroablation has only a placebo effect. For example, Steele et al. found that better clinical outcomes of anterior cingulotomy were associated first with anterior lesions compared to posterior lesions, and second with smaller lesions [106]. If lesion localisation and volume do predict the outcome, this provides evidence against the hypothesis that anterior cingulotomy is a nonspecific or mere placebo treatment [106]. However, further research is necessary to validate this hypothesis.

Important to note is that for OCD, neuroablation (radiofrequency thermocoagulation and radiosurgery) has higher response rates than DBS and is safer than DBS [40, 42]. Based on the available evidence, we think that treatment guidelines should recommend anterior capsulotomy for selected patients with severe, treatment-refractory OCD. According to the Strength of Recommendation Taxonomy (SORT), the recommendation should be of level B, i.e., a "recommendation based on inconsistent or limited quality patient-oriented evidence" [107]. For a level A recommendation based on consistent and good-quality patient-oriented evidence, a well-designed and adequately powered randomised controlled trial showing patient-relevant clinical differences between anterior capsulotomy and best practice standard of care would be required [107].

\section{Recommendations for Gamma Knife Radiosurgery}

Gamma Knife radiosurgery has been used in the psychiatry field since the 1950 s [33]. However, the number of psychiatric patients treated with Gamma Knife in recent years is small.

A systematic review by Miguel et al. examined 13 studies (ranging from 3 to 55 patients) of Gamma Knife for OCD, reporting response rates between $25 \%$ and $71.4 \%$ and an average Y-BOCS reduction of $36.4 \%$ to $74.6 \%$ [108].
The largest study included in the review enrolled 55 OCD patients and reported a response rate of $56 \%$ [109]. Because this study was not double-blind or placebo controlled, placebo effects cannot be ruled out. However, it is unlikely that the observed effects were placebo effects. The main argument against a placebo effect is that the first patients were treated with one shot, but this treatment did not reduce the Y-BOCS statistically significantly. Most of these patients received a second shot. After that, a significant Y-BOCS reduction occurred. Another group of patients received a double-shot treatment, and this group also showed a significant Y-BOCS reduction. The study authors had expected that the single shot lesion alone would be effective, but this was not the case. Only the treatment with two shots (either single shot repeated or double-shot) was effective.

An international, multicentre, retrospective cohort study of gamma ventral capsulotomy (40 patients) reports $45 \%$ responders (40\% in remission) [110].

Very few studies have investigated Gamma Knife for MDD. In a single case study, a patient who had suffered from severe depression for 30 years and made nine suicide attempts experienced a HAM-D reduction of $82.6 \%$ four months after Gamma Knife subcaudate tractotomy [111]. In an open label study with three patients, a mean BDI reduction of $65 \%$ was observed 2 years after Gamma Knife cingulotomy [33].

In general, the time course of the success of Gamma Knife treatment in psychiatric indications was similar to that of other functional indications. This speaks against the fact that this procedure has only a placebo effect [111].

Gamma Knife RCTs are technically feasible since the patients cannot perceive whether they are treated or not. However, with elder Gamma Knife models, sham treatments would be ethically problematic because also the sham group would receive considerable radiation. Therefore, for studies with these models it would be necessary to provide a special shelter against radiation for the sham group. These technical hurdles may explain why, until now, only one Gamma Knife RCT has been performed for any psychiatric disorder.

The first (and only) Gamma Knife RCT with OCD patients showed an average Y-BOCS reduction of $28.6 \%$ in the treatment group vs. $5.8 \%$ in the sham 
group after 12 months [112]. The response rate in the treatment group was $25 \%$ ( 2 out of 8 patients) vs. $0 \%$ in the sham group ( 0 out of 8 patients) [112]. However, the differences between the two groups were not statistically significant [112].

With the newer Perfexion ${ }^{\circledR}$ and ICON® Gamma Knife models, radiation sources remain fully covered so that patients do not receive radiation while they lie in the machine. Consequently, the main ethical argument against Gamma Knife RCTs would not apply when one of these models is used.

Gamma Knife RCTs for OCD could nevertheless be ethically problematic because there is no clinical equipoise between the treatment and control groups (i.e., the control group would be probably disadvantaged). Although the available evidence for the efficacy of Gamma Knife treatments for OCD is not yet sufficient for a strong recommendation, it is strong enough to question the clinical equipoise. This is of particular relevance because the sham-controlled period must last at least one year before the treatment effects can completely manifest. Furthermore, we expect that patients would not participate in an RCT if they could receive treatment directly in other facilities. Therefore, the acquisition of a sufficient number of patients would be a difficult and time-consuming process that would certainly necessitate a multi-centre study.

The available evidence supports a level B recommendation according to SORT [107] for Gamma Knife radiosurgery in selected patients with severe, treatment-refractory OCD.

Recommendations for Magnetic Resonance-guided Focused Ultrasound (MRgFUS)

Very recently, MRgFUS has been introduced into psychiatric neurosurgery [29, 113]— [115]. MRgFUS has proven efficacy, safety, and cost-efficiency for essential tremor [34, 44] plus cost-efficiency for OCD [46].

In a study of MRgFUS for OCD, $54.6 \%$ of patients (6 of 11) were responders after 24 months [30]. The mean Y-BOCS reduction was $38.1 \%$. Additionally, depression and anxiety decreased significantly. Participants' neuropsychological functions were unchanged or partly improved, and no significant psychiatric or behavioural adverse events were reported. During treatment, patients only experienced mild adverse effects, which resolved after the treatment [30]. Although
OCD symptoms began to decrease only one week after treatment, the improvement further increased during the 24-month observation period [30]. Another study of MRgFUS for OCD reported similar results: $66.7 \%$ of patients (4 of 6) were responders, and the mean Y-BOCS reduction was 33.3\% [114].

In a MRgFUS study for MDD, all four patients responded to the treatment with an at least $50 \%$ improvement in the HAM-D total score [116]. Permanent physical, neurological or psychological complications were not observed, but the body weight of all patients increased (mean weight: $+7.5 \mathrm{~kg}$ after 12 months) [116]. A further MRgFUS study for MDD reported that $33.3 \%$ of patients (2 of 6 ) responded [114].

MRgFUS capsulotomy did not adversely impact cognitive function across several domains (study with 5 OCD and 5 MDD patients) [113].

Although these first experiences are promising, two small uncontrolled studies are not sufficient to prove the effectiveness of MRgFUS for OCD or to comprehensively evaluate its risk profile. Therefore, we recommend that two different research groups carry out RCTs independently of each other.

However, it is not known whether effective blinding is possible in trials of MRgFUS because many patients feel heat, headaches, and vestibular symptoms during the treatment. In an RCT for essential tremor, most patients correctly guessed their assignment to the treatment vs. sham group, respectively [117]. To solve this, harmless side-effects could be reproduced in the control group, or side-effects should be completely suppressed in the treatment group through drugs.

\section{Recommendations for Deep Brain Stimulation}

The spectrum of psychiatric indications for DBS has broadened: currently DBS is trialled for OCD, MDD, Tourette syndrome, aggressive disorder, anorexia nervosa, drug addiction, schizophrenia, severe adiposity, and Alzheimer's dementia [13, 118].

Most psychiatric DBS studies are small, open-label studies, of which most report impressive response rates. However, the results of these trials are inconclusive and have not been confirmed by RCTs so far. For DBS, RCTs are technically feasible and ethically justifiable. However, most DBS RCTs to date 
have been conducted in OCD and major depressive disorder.

In RCTs, two types of sham-control can be used: (i) Staggered-onset, in which patients are randomized to active vs. sham stimulation in a blinded fashion for several months, followed by an open-label continuation phase, in which all patients receive active stimulation; (ii) Cross-over, in which all patients receive active stimulation after surgery, and the stimulation parameters are individually optimized. After several weeks or months of stimulation in the first group, the stimulation is switched off without the patients' knowledge. After a certain period, the stimulation is switched on again in the first group, whereas it is switched off in the second group. Therefore, patients can be compared with and without active stimulation. However, if symptoms worsen after switching off the stimulation, this does not prove the effectiveness of DBS, but may instead be a carry-over effect, comparable to withdrawal symptoms after the discontinuation of opiates. Furthermore, the blinding of the patients is also questionable in DBS RCTs: The authors of a DBS crossover RCT for treatmentresistant MDD admitted: "Although these patients [in the cross-over phase] were blinded to active vs sham DBS, they could accurately predict the stimulation setting" [119]. Therefore, cross-over studies cannot adequately investigate the effectiveness of the stimulation. Rather, they investigate the effect of the sudden withdrawal of stimulation. Additionally, the often-described exacerbation of symptoms after DBS battery depletion does not prove the efficacy of DBS but might rather be a withdrawal effect.

The problem of both study types is that all patients are operated on, so placebo effects and lesion effects have to be expected for all patients. Therefore, strictly speaking, no real sham-controlled DBS studies have yet been performed with psychiatric patients. For that, another control group would be necessary that receives a sham operation without electrode implantation. However, this must not be done for ethical reasons.

For OCD, ten different targets have been tested to date [120]. A review by Kohl et al. including 25 papers with a total of 109 patients found response rates ranging from $45.5 \%$ to $100 \%$ [121]. A review by Pepper et al. including 10 studies with a total of 62 patients reported an average response rate of $52 \%$ [42]. However, these reviews comprise mostly uncontrolled studies. A recent systematic review by Vicheva et al. comprising eight RCTs with a total of 80 patients found a pooled mean reduction in Y-BOCS of $38.7 \%$ [120].

A systematic review and meta-analysis from Kisely et al. including five RCTs (44 patients in total) found statistically significant differences between sham and real DBS stimulation [122]. However, all but one study (including 6 patients) [123] adopted a cross-over design, so placebo effects due to carryover effects cannot be excluded [120].

Indeed, a meta-analysis of individual patient data (four RCTs, including a total of 49 patients) found that sham stimulation also induced a significant reduction in the Y-BOCS score [124]. This suggests that placebo and/or micro-lesion effects also exist in DBS for OCD [124].

Vicheva et al. state: "DBS for OCD remains strictly experimental and is reserved only for carefully selected patients" [120]. In 2017, the Royal College of Psychiatrists states that "all DBS procedures for all psychiatric indications" are "investigational" and "should not be performed unless as part of an ethically approved research protocol" [56]. According to the consensus guidelines of the World Society for Stereotactic and Functional Neurosurgery (WSSFN) published in 2014, a therapy becomes established when "at least two blinded randomized controlled clinical trials from two different groups of researchers are published, both reporting an acceptable risk-benefit ratio, at least comparable with other existing therapies. The clinical trials should be on the same brain area for the same psychiatric indication." [21]. In 2021, the WSSFN states that for otherwise treatment-refractory OCD, DBS "in the ventral anterior capsule region (including bed nucleus of stria terminalis and nucleus accumbens) remains investigational. It represents an emerging, but not yet established therapy." [23]. This statement is based on two blinded RCTs (one with level I evidence, the other with level II evidence), a clinical cohort study, and a prospective international multi-centre study [23]. This WSSFN statement represents "a step forward", but the authors emphasize that in order to meet the WSSFN criteria of the 2014 consensus paper [21], "at least one additional, welldesigned, blinded clinical trial will be necessary" [23]. They state: "Until then, surgery can be offered for refractory OCD based on the promising data obtained thus far, albeit with proper regulatory oversight. In the 
US, despite the FDA HDE approval statement from 2009, review by an institutional review board (IRB) remains necessary. It is our view that in whatever jurisdiction within which a surgeon practices, it is in the interest of patients and the integrity of the work that until DBS in OCD is fully vetted as an established therapy, surgeons consult their local IRB and/or research ethics committees when undertaking investigational procedures and as required by local jurisdictional laws and prevailing norms. Surgery for OCD remains a treatment of last resort, and careful patient selection according to clear definitions of "treatment refractoriness' is recommended." [23]. The authors encourage researchers and clinicians to conduct RCTs to further evaluate this treatment as well as to investigate suitable brain targets [23].

We fully agree with this recommendation. Additionally, we recommend that DBS for treatmentrefractory OCD should be offered only in specialized centres that perform ethically approved trials and have enough experience with this treatment. Although this leads to travel burden and extra costs for some patients, the treatment in specialized centres has great advantages for patients with regard to the effectivity and safety of the intervention. Performing DBS for psychiatric indications requires specialized training, much experience and a high level of multidisciplinary expertise with regard not only to the surgery, but also to patient selection, patient information, device programming, and preand postsurgical neurological and psychiatric assessment [15]. This high level can only be provided at specialized centres. For research, we strongly recommend to conduct RCTs with staggered onset, because they are necessary to exclude placebo effects and withdrawal effects.

For major depressive disorder, several small openlabel DBS studies have been performed. They focus on white matter adjacent to the subcallosal cingulate cortex (SCC), the anterior limb of the internal capsule (ALIC), the ventral capsule/ventral striatum (VC/ VS), the superolateral branch of the median forebrain bundle (slMFB), and the nucleus accumbens (NAcc) [125].

According to a systematic review and meta-analysis by Zhou et al. (including 14 DBS studies in four different brain targets), the pooled response rate was $48 \%$, and the pooled remission rate was $30 \%$ after 12 months
[126]. ${ }^{19}$ Because most studies are uncontrolled, neither the placebo effect nor the effect of the surgery itself can be excluded [125].

A meta-analysis of seven RCTs (five cross-over and two staggered-onset studies) showed that active stimulation was associated with a significantly greater treatment response than sham stimulation [125]. However, this result was no longer significant when the cross-over studies were excluded and only the staggered-onset studies were analysed [125].

Two large staggered-onset DBS studies on treatment-resistant MDD were discontinued prematurely by the device manufacturers who financed the studies (Medtronic Inc. and St Jude (now Abbott)), because a futility analysis could not establish the superiority of stimulation over sham stimulation (VC/VS, RECLAIM trial, [127]; SCC, BROADEN trial, [128]). A third RCT with staggered onset was completed, but also failed to show a significant difference between sham and active stimulation (sIMFB, FORESEE II trial, [129]).

In summary, all three staggered-onset RCTs for DBS in MDD failed to show a significant difference between active and sham stimulation. Given these disappointing results, DBS for MDD is not yet clinically viable.

For Alzheimer's dementia, several small investigational studies of DBS of the fornix [130], the nucleus basalis of Meynert [131], and the VC/VS [132] have been performed. By design, these studies cannot provide conclusive evidence and can only inform whether or not additional larger clinical trials are warranted. So far, only one adequately powered RCT has been performed to investigate DBS of the fornix for Alzheimer's dementia [133]. The results of this trial are inconclusive and do not show a clinically important difference between the treatment and control groups [134]. However, the procedure is associated with significant neurosurgical procedurerelated medical harms and adverse events, as well as a high research burden for the patients [134].

So far, there have been no real treatment successes of DBS in Alzheimer's dementia, even though some researchers may argue so. The claimed successes are

\footnotetext{
19 Response was defined as a $50 \%$ reduction in the severity of depression as measured by MADRS or HDRS. Remission was defined as an HDRS-17 score $<8$, an HDRS-28 score $<10$, or a $>75 \%$ reduction in MADRS [126].
} 
based only on cherry-picking of data, i.e., presenting as successes the few patients whose dementia symptoms had increased less than average [134]. Instead of publishing the long-term data of previous patients, the researchers include ever-new patients in new studies [134].

The plethora of hypotheses justifying DBS for Alzheimer's dementia are neither based on suitable animal studies nor linked to the leading scientific theories on the causes of Alzheimer's dementia, including the inflammation hypothesis [134].

Ethically, DBS research on Alzheimer's patients is particularly problematic: Even if patients are able to give consent at the beginning of the study, it is very likely that they will lose this ability over the course of treatment. Furthermore, DBS exposes Alzheimer's patients to particularly high risks and burdens because DBS and general anaesthesia are particularly risky for older people and dementia patients [134]. Furthermore, hospitalization often causes significant harm to patients with dementia [135].

Furthermore, there may be more promising treatment options than DBS for people with Alzheimer's dementia that have fewer risks and burdens, and perhaps a higher efficacy. Anti-inflammatory drugs seem to be effective for preventing dementia, particularly the anti-rheumatic drug etanercept (an anti-TNF agent) [136]. Whether the antibody aducanumab is effective for Alzheimer's dementia in higher doses has yet to be determined [137].

On the basis of the available evidence and ethical considerations, we recommend terminating DBS research for Alzheimer's dementia in order to prevent further harm to patients [134].

\section{Recommendations for Dealing with "Failed Studies"}

A highly controversial issue is how to deal with failed studies in psychiatric neurosurgery research. The main controversy relates to three DBS RCTs on major depressive disorder, which unexpectedly could not reproduce the success rates of small open label studies and some cross-over studies. These three studies have failed insofar as their hypotheses - namely that the stimulation has a significant effect on the depression score - have been falsified. If the criteria of pharmaceutical research were applied, these failures would mean the definitive end of treating MDD with DBS in these three target brain areas. However, several DBS researchers do not accept the failed studies as failures of the method.

Cavuoto commented: "In our view, the FDA needs to understand the vital importance of getting firstgeneration devices into the field and move away from arbitrary standards like improving symptoms by 50 percent in $50 \%$ of the population. The notion that if we can't help everybody we shouldn't help anybody has no place in medical science, particularly when you consider that neuromodulation therapies are working with the hardest-case patients who have not responded to other therapies." [138].

Schläpfer wrote: "Do these studies convincingly demonstrate that DBS is inefficacious and clinically useless for the treatment of major depression? I believe that these are examples of failed studies and not failed treatments. There is convincing evidence of antidepressant efficacy for all three targets mentioned as well as for another target, the superolateral branch of the medial forebrain bundle. These data were not obtained in sham-controlled studies but from openlabel studies and case series - albeit in patient populations that did not respond to dozens of treatment attempts with psychotherapy, psychopharmacology, and electroconvulsive treatment." [139].

In our view, these three failed studies do not prove that DBS has no place in the treatment of major depression because the possibility cannot be excluded that a better study design would produce better results. $^{20}$

Proponents of DBS for MDD criticize the failed studies for having used depression scales instead of quality of life (QoL) scales [139]. However, this is not convincing because QoL scales have been used in other studies but did not show significantly differences between the sham and active stimulation groups.

Another criticism is that the two-month doubleblinding period in the slMFB study was too short [129]. However, the other two RCTs [127, 128] had double-blinding periods of four and six months,

\footnotetext{
${ }^{20}$ Schläpfer has rightly criticized that in the Dougherty study [127], the individual stimulation parameters were left unchanged for the four-month sham-controlled period, although, in all published studies, parameters were adapted over months to reach optimal antidepressant efficacy [139].
} 
respectively, and also showed no significant difference between the sham and the stimulation group.

Furthermore, it has been argued that the increased response rate during the open-label study after the double-blinded period illustrates the need for longer trials [140]. However, the fact that some patients from both the sham and active stimulation groups became responders in the open-label phase after the doubleblind phase is no valid argument for the efficacy of the stimulation. Indeed, the response might have been caused by the placebo effect that was previously prevented by double-blinding.

Overall, these explanations seem to show a strategy of self-immunization against criticism. After the hypothesis has been falsified, the commentators question the self-chosen research plan, measuring instruments, and primary treatment goals. This would surely not happen if the hypothesis had been proven.

A more detailed strategy has been elaborated by the working group "Deep Brain Stimulation for Psychiatric Disorders: Measuring Outcomes and Institutionalizing Ethical Standards". ${ }^{21}$ In their paper "Being open minded about neuromodulation trials: Finding success in our "failures" [141], the working group demands that failed studies should not lead to "a premature closure of inquiry." They argue that existing research methodologies are derived from drug trials, and "ill-suited to invasive device trials" [141]. They further argue that "device studies may be closed or characterized as 'failures' in light of interim futility analyses before knowledge embedded in them can be fully mined" [141]. They suggest an "alternate research methodology" and demand that we "shift our gaze from research failure to those occasions when hypothesis yield positive results" [141].

This recommendation of a more flexible study design - which allows the individual adaptation of stimulation targets and the modification of certain aspects of study design based on what has been learned during the study [141] - is worth further investigation.

However, the working group's suggestion on shifting our gaze to the cases with a positive outcome is

\footnotetext{
21 The working group consists of psychiatric neurosurgery researchers, namely Helen Mayberg, Cynthia Kubu, Bart Nuttin, and Thomas Schläpfer, plus the bioethicist Joseph Fins and the legal theorist Reinhard Merkel.
}

problematic. If the cases with positive outcomes share certain targeting characteristics, stimulation parameters, demographic properties, or clinical characteristics, it may be that their analysis could unveil the factors that determine success or failure of DBS. However, it is always possible to find certain common characteristics among the responder group: Perhaps all patients with blue eyes are responders, or perhaps all patients with more ventral stimulation were responders. Whether or not common characteristics of the responder group are relevant or only incidental cannot be deducted from these studies but only through further studies with greater statistical power. In the next study, the selected group may not be a particular success but instead a particular failure. Due to the extremely small number of patients in previous DBS studies, the suggested strategy bears a high risk of cherry-picking data.

The disappointing results of the RCTs should not be discussed away. Of course, it is possible that the studies were poorly designed, and that a betterdesigned study might be justified under certain circumstances. However, if further studies also fail, further research should be discontinued in order to avoid exposing further patients to unnecessary burdens and risks.

It is important to note that the above-mentioned studies are not failures in each regard: On average, the treatments had a moderate to large anti-depressant effect, but the DBS stimulation did not make a difference.

There may be different reasons for the discrepancy between successful small open-label studies and cross-over RCTs vs. failed staggered-onset RCTs. First, the small open-label studies might have shown only placebo or doctor effects due to intensive attention to study participants from the medical staff and due to the use of an expensive, high-tech treatment that has been hyped in the media. Perhaps the discrepancy can be explained by the "efficacy paradox" [87], which can occur when the overall effect is large, but driven by a large placebo effect and a comparatively small treatment-specific effect. Second, in cross-over RCTs, the difference between sham and active stimulation groups might be mainly caused by withdrawal effects. Third, the effects of DBS might be mainly lesion effects, which do not differ much between the sham and active stimulation groups.

We do not think that DBS effects are only placebo or doctor effects. However, we hypothesize that DBS 
is successful in part due to the lesion effect. Therefore, we think that it is important to further investigate ablative neurosurgery, particularly in the slMFB, where the immediate effect of DBS was greatest.

The considerations in this section naturally apply to failed studies of other procedures besides DBS as well.

\section{Discussion: Recommendation for Transferring Research to the Clinical Practice}

We agree with the Royal Society of Psychiatrists that most activities of psychiatric neurosurgery represent research and not "established care" [56]. We also agree with the WSSFN statement that DBS for OCD in the ventral anterior capsule region is an emerging, but not yet established therapy, and that surgery for OCD remains a treatment of last resort [23]. However, for carefully selected patients with chronic, treatment-refractory mental disorders, neurosurgical therapy might be a good option.

We recommend that methods with good evidence for effectiveness and an acceptable risk profile should be rapidly transferred into clinical practice. In our opinion, this currently concerns DBS and anterior capsulotomy with Gamma Knife radiosurgery or radiofrequency thermocoagulation for OCD. Patients for whom psychotherapy and drug therapies (including unconventional therapies) have been exhausted should have access to these treatment options.

For each patient, the risks and benefits of surgery must be balanced with the risks and benefits of continuing with treatment as usual [56].

The key factor is that the gatekeepers - namely psychiatrists and psychotherapists - inform patients adequately and refer patients for whom psychiatric neurosurgery could be an option to clinics that offer this treatment. Currently, the referral practice is probably too conservative because most psychiatrists have strong concerns about psychiatric neurosurgery. As discussed here, concerns regarding scientific evidence are justified, but some concerns are based on a lack of knowledge or ideological reservations. As a result, many patients with severe psychiatric disorders receive effective treatment much too late or not at all. In order to improve this situation, psychiatric neurosurgery needs to gain the trust of the psychiatrists, and for this, it is essential to address the concerns discussed above appropriately.

Patients need comprehensive information and advice on all treatment options and their respective risk-benefit profiles.

When researchers recruit patients for basic research studies, they should actively counteract the therapeutic misconception ${ }^{22}$ and not pressure despaired patients to participate in experiments with exaggerated promises.

Because the outcomes of the different psychiatric neurosurgery procedures are largely comparable, the counselling of patients has to be highly individualized [25]. Individual factors should play a crucial role in decision-making. In particular, these individual factors include the patients' preferences and attitudes, e.g., whether they can tolerate implanted devices, whether they are afraid of the irreversibility of an ablative procedure, or whether they would not accept the physician's control over their mental states through manipulation of DBS stimulation settings. The pre-treatment consultation should explicitly address both the risk and the chance of temporary or permanent changes of personality traits. Psychoeducation programs should be offered to provide patients and caregivers with psychosocial support in the months following surgery [72]. Furthermore, patients' social and economic situation, professional activity, access to DBS centres, and geographical mobility have to be considered carefully in counselling. This includes whether patients can afford the costs of a given therapy and follow-up, whether they can come regularly to the clinic, and the extent to which they are supported by family members or friends.

The counselling should also include therapy options that are not affiliated with the institution that performs the procedure, even if the consequence is that the patient will be treated in another institution or lost as a research participant. A multidisciplinary team should assist patients in the decision-making process. If such a team does not exist locally, the patients should be referred to clinicians who specialise in all relevant therapies under consideration.

\footnotetext{
$\overline{22}$ Therapeutic misconception occurs when research subjects fail to appreciate the distinction between the imperatives of clinical research and ordinary treatment [142].
} 
Interventions into the "organ of the mind" fall into a special category of the medical use of neural devices in clinical or research settings that raise expectations about consent, communication, and surgeon-patient interaction that acknowledge the humanistic approach to patient-physician relationships. Physicians, clinical researchers, and funders are all jointly responsible for anticipating possible care needs after the participation in a DBS research study or after safe discharge after DBS has been performed as a clinical treatment [143]. However, due to the high stakes of undergoing psychiatric neurosurgery, fostering trustful and enduring relationships is essential as well as followup offers that engage with personal patient needs and account for caregiver perspectives in setting psychiatric follow-up care provisions [77]. For psychiatric neurosurgical research, paying attention to the humanistic dimensions in medicine also requires to evaluate these treatments using patient-reported outcomes such as quality of life that encompass broader indicators of disease burden and patient-relevant outcomes [144].

Acknowledgements This paper has been written within the framework of the ERA-NET NEURON project, "Psychiatric Neurosurgery - Ethical, Legal and Societal Issues." Sabine Müller and Merlin Bittlinger's work for this paper was funded by the Federal Ministry of Research and Education (BMBF), Germany (grant number: 01GP1621A). Roberto MartínezÁlvarez received funding from the National Institute of Health Carlos III, Spain.

Author Contributions Conceptualization: Sabine Müller; Writing - original draft preparation: Sabine Müller; Writing - review and editing: Sabine Müller, Ansel van Oosterhout, Chris Bervoets, Markus Christen, Roberto Martínez-Álvarez, Merlin Bittlinger; literature search and data analysis: Sabine Müller, Merlin Bittlinger, Markus Christen; revision of the paper: Sabine Müller, Merlin Bittlinger, Markus Christen; funding acquisition: Sabine Müller, Roberto Martínez-Álvarez.

Funding Open Access funding enabled and organized by Projekt DEAL.

\section{Declarations}

Conflict of interest All authors declare that they have no conflict of interest.

Open Access This article is licensed under a Creative Commons Attribution 4.0 International License, which permits use, sharing, adaptation, distribution and reproduction in any medium or format, as long as you give appropriate credit to the original author(s) and the source, provide a link to the Creative
Commons licence, and indicate if changes were made. The images or other third party material in this article are included in the article's Creative Commons licence, unless indicated otherwise in a credit line to the material. If material is not included in the article's Creative Commons licence and your intended use is not permitted by statutory regulation or exceeds the permitted use, you will need to obtain permission directly from the copyright holder. To view a copy of this licence, visit http://creativecommons.org/licenses/by/4.0/.

\section{References}

1. Rzesnitzek, L., M.I. Hariz, and J.K. Krauss. 2020. Psychosurgery in the history of stereotactic functional neurosurgery. Stereotactic and Functional Neurosurgery 98 (4): 241-247. https://doi.org/10.1159/000508167.

2. Chodakiewitz, Y., J. Williams, J. Chodakiewitz, G. R. Cosgrove. 2015. Ablative surgery for neuropsychiatric disorders: past, present, future. In Neurosurgical treatments for psychiatric disorders, ed. Bomin Sun and Antonio De Salles, 51-66. Dordrecht: Springer. https:// doi.org/10.1007/978-94-017-9576-0_5.

3. Diering, S.L., and W.O. Bell. 1991. Functional neurosurgery for psychiatric disorders: A historical perspective. Stereotactic and Functional Neurosurgery 57: 175-194. https://doi.org/10.1159/000099570.

4. Lévèque, M. 2013. Psychosurgery: New techniques for brain disorders. Heidelberg et al.: Springer.

5. Valenstein, E.S. 1986. Great and desperate cures: The rise and decline of psychosurgery and other radical treatments for mental illness. New York: Basic Books, Inc., Publishers.

6. Nudeshima, J., and T. Taira. 2017. A brief note on the history of psychosurgery in Japan. Neurosurgical Focus 43 (3): E13. https://doi.org/10.3171/2017.6.FOCUS17255.

7. US Department of Health. 1977. Education, and Welfare (1977) Protection of human subjects: Use of psychosurgery in practice and research: Report and recommendations of National Commission for the Protection of Human Subjects. Federal Register 42 (99): 26318-26332.

8. Müller, S. 2017. Ethical challenges of modern psychiatric neurosurgery. In Neuroethics. Anticipating the future, ed. Judy Illes, 235-263. Oxford: Oxford University Press.

9. Rush, A.J., M.H. Trivedi, S.R. Wisniewski, A.A. Nierenberg, J.W. Stewart, D. Warden, et al. 2006. Acute and longerterm outcomes in depressed outpatients requiring one or several treatment steps: A STAR * D report. The American Journal of Psychiatry 163: 1905-1917. https://doi.org/10. 1176/ajp.2006.163.11.1905.

10. Mansouri, A., S. Taslimi, J.H. Badhiwala, C.D. Witiw, F. Nassiri, V.J.J. Odekerken, et al. 2018. Deep brain stimulation for Parkinson's disease: Meta-analysis of results of randomized trials at varying lengths of follow-up. Journal of Neurosurgery 128 (4): 1199-1213. https://doi.org/ 10.3171/2016.11.JNS16715.

11. Limousin, P., and T. Foltynie. 2019. Long-term outcomes of deep brain stimulation in Parkinson disease. Nature 
Reviews Neurology 15 (4): 234-242. https://doi.org/10. 1038/s41582-019-0145-9.

12. Hariz, M.I., P. Blomstedt, and L. Zrinzo. 2013. Future of brain stimulation: New targets, new indications, new technology. Movement Disorders 28 (13): 1784-1792. https://doi.org/10.1002/mds.25665.

13. Lozano, A.M., N. Lipsman, H. Bergman, P. Brown, S. Chabardes, J.W. Chang, et al. 2019. Deep brain stimulation: Current challenges and future directions. Nature Reviews Neurology 15 (3): 148-160. https://doi.org/10. 1038/s41582-018-0128-2.

14. Mundale, J. 2016. Reversibility and deep brain stimulation. Journal of Cognition and Neuroethics 3 (4): 97-111.

15. Christen, M., C. Ineichen, M. Bittlinger, H.-W. Bothe, and S. Müller. 2014. Ethical focal points in the international practice of deep brain stimulation. AJOB Neuroscience 5 (4): 65-80. https://doi.org/10.1080/21507740. 2014.939380.

16. Coenen, V.A., F. Amtage, J. Volkmann, and T.E. Schläpfer. 2015. Deep brain stimulation in neurological and psychiatric disorders. Deutsches Ärzteblatt International 112: 519-526. https://doi.org/10.3238/arztebl.2015.0519.

17. Luigjes, J., de Kwaasteniet, P. P. de Koning, M. S. Oudijn, P. van den Munckhof, P. R. Schuurman, et al. 2013. Surgery for psychiatric disorders. World Neurosurgery 80 (3/4): S31.e17-28. https://doi.org/10.1016/j. wneu.2012.03.009.

18. Bell, E., P. Leger, T. Sankar, and É. Racine. 2016. Deep brain stimulation as clinical innovation: An ethical and organizational framework to sustain deliberations about psychiatric deep brain stimulation. Neurosurgery 79 (1): 3-9. https://doi.org/10.1227/NEU.0000000000001207.

19. Fins, J.J., T.E. Schläpfer, B. Nuttin, C.S. Kubu, T. Galert, V. Sturm, et al. 2011. Ethical guidance for the management of conflicts of interest for researchers, engineers and clinicians engaged in the development of therapeutic deep brain stimulation. Journal of Neural Engineering 8 (3): 03301. https://doi.org/10.1088/1741-2560/8/3/ 033001.

20. Grant, R.A., C.H. Halpern, G.H. Baltuch, J.P. O'Reardon, and A. Caplan. 2014. Ethical considerations in deep brain stimulation for psychiatric illness. Journal of Clinical Neuroscience 21: 1-5. https://doi.org/10.1016/j.jocn. 2013.04.004.

21. Nuttin, B., H. Wu, H. Mayberg, M.I. Hariz, L. Gabriëls, T. Galert, et al. 2014. Consensus on guidelines for stereotactic neurosurgery for psychiatric disorders. Journal of Neurology, Neurosurgery, and Psychiatry 85 (9): 10031008. https://doi.org/10.1136/jnnp-2013-306580.

22. Rabins, P., B.S. Appleby, J. Brandt, M.R. DeLong, L.B. Dunn, L. Gabriëls, et al. 2009. Scientific and ethical issues related to deep brain stimulation for disorders of mood, behavior, and thought. Archives of General Psychiatry 66: 931-937. https://doi.org/10.1001/archgenpsychiatry.2009. 113.

23. Wu, H., M.I. Hariz, V. Visser-Vandewalle, L. Zrinzo, V.A. Coenen, S.A. Sheth, et al. 2021. Deep brain stimulation for refractory obsessive-compulsive disorder (OCD): Emerging or established therapy? Molecular Psychiatry 26 (1): 60-65. https://doi.org/10.1038/s41380-020-00933-x.
24. European Commission. Internal Market, Industry, Entrepreneurship and SMEs. https://doi.org/https://ec.europa. eu/growth/single-market/ce-marking/. Accessed 17 October 2021.

25. Arya, S., M.M. Filkowski, P. Nanda, and S.A. Sheth. 2019. Deep brain stimulation for obsessive-compulsive disorder. Bulletin of the Menninger Clinic 83 (1): 84-96. https://doi.org/10.1521/bumc.2019.83.1.84.

26. Niranjan, A., L.D. Lunsford, and H. Kano, eds. 2019. Leksell Radiosurgery. Basel: Karger.

27. Sun, B., and A. De Salles, eds. 2015. Neurosurgical treatments for psychiatric disorders. Dordrecht: Springer.

28. Brown, L.T., C.B. Mikell, B.E. Youngerman, Y. Zhang, G.M. McKhann 2nd., and S.A. Sheth. 2016. Dorsal anterior cingulotomy and anterior capsulotomy for severe, refractory obsessive-compulsive disorder: A systematic review of observational studies. Journal of Neurosurgery 124: 77-89. https://doi.org/10.3171/2015.1.JNS14681.

29. Davidson, B., C. Hamani, Y. Huang, R.M. Jones, Y. Meng, P. Giacobbe, and N. Lipsman. 2020. Magnetic resonance-guided focused ultrasound capsulotomy for treatment-resistant psychiatric disorders. Operative Neurosurgery (Hagerstown). 19 (6): 741-749. https://doi.org/ 10.1093/ons/opaa240.

30. Kim, S.J., D. Roh, H.H. Jung, W.S. Chang, C.-H. Kim, and J.-W. Chang. 2018. A study of novel bilateral thermal capsulotomy with focused ultrasound for treatmentrefractory obsessive-compulsive disorder: 2-year follow-up. Journal of Psychiatry and Neuroscience 43 (5): 327-337. https://doi.org/10.1503/jpn.170188.

31. Lunsford, L. D., A. Niranjan, A. Fallon, J. O. Kim. 2019. Frame versus frameless Leksell stereotactic radiosurgery. In Leksell Radiosurgery, ed. A. Niranjan, L. D. Lunsford, and H. Kano, 19-27. Basel: Karger. https://doi.org/10. 1159/000493046.

32. Martínez-Álvarez, R. 2015. Ablative surgery for obsessive-compulsive disorders. In Neurosurgical treatments for psychiatric disorders, ed. B. Sun and A. De Salles, 105-112. Dordrecht: Springer. https://doi.org/10.1007/ 978-94-017-9576-0_10.

33. Martínez-Álvarez, R. 2019. Behavioral radiosurgery. In Leksell radiosurgery, ed. A. Niranjan, L. D. Lunsford, and H. Kano, 289-297. Basel: Karger. https://doi.org/10. 1159/000493076.

34. Schreglmann, S.R., S. Hägele-Link, B. Werner, E. Martin, and G. Kägi. 2018. Focused ultrasound ablation as tremor treatment. Der Nervenarzt 89: 674-681. https://doi.org/10. 1007/s00115-017-0470-4.

35. Volpini, M., P. Giacobbe, G.R. Cosgrove, A. Levitt, A.M. Lozano, and N. Lipsman. 2017. The history and future of ablative neurosurgery for major depressive disorder. Stereotactic and Functional Neurosurgery 95: 216-228. https://doi.org/10.1159/000478025.

36. Cabrera, L.Y., C. Courchesne, Z.H.T. Kiss, and J. Illes. 2019. Clinical perspectives on psychiatric neurosurgery. Stereotactic and Functional Neurosurgery 97 (5-6): 391398. https://doi.org/10.1159/000505080.

37. Matusall, S., M. Christen, and I. Kaufmann. 2011. The emergence of social neuroscience as an academic discipline. In The Oxford Handbook of Social Neuroscience, 
ed. J. Decety and J. Cacioppo, 9-27. New York: Oxford University Press.

38. Balachander, S., S. Sundar Arumugham, and S. Dwarakanath. 2019. Ablative neurosurgery and deep brain stimulation for obsessive-compulsive disorder. Indian Journal of Psychiatry 61 (Suppl 1): S77-S84. https://doi.org/10.4103/psychiatry. IndianJPsychiatry_523_18.

39. Stahl, D., L.Y. Cabrera, and T. Gibb. 2018. Should DBS for psychiatric disorders be considered a form of psychosurgery? Ethical and legal considerations. Science and Engineering Ethics 24: 1119-1142. https://doi.org/10. 1007/s11948-017-9934-y.

40. Kumar, K.K., G. Appelboom, L. Lamsam, A.C. Caplan, N.R. Williams, M.T. Bhati, et al. 2019. Comparative effectiveness of neuroablation and deep brain stimulation for treatment-resistant obsessive-compulsive disorder: A meta-analytic study. Journal of Neurology, Neurosurgery, and Psychiatry 90: 469-473. https://doi.org/10. 1136/jnnp-2018-319318.

41. Müller, S., R. Riedmüller, and A. van Oosterhout. 2015. Rivaling paradigms in psychiatric neurosurgery: Adjustability versus quick fix versus minimal-invasiveness. Frontiers in Integrative Neuroscience 9: 27. https://doi. org/10.3389/fnint.2015.00027.

42. Pepper, J., M.I. Hariz, and L. Zrinzo. 2015. Deep brain stimulation versus anterior capsulotomy for obsessivecompulsive disorder: A review of the literature. Journal of Neurosurgery 122 (5): 1028-1037. https://doi.org/10. 3171/2014.11.JNS132618.

43. Pepper, J., Zrinzo, Hariz, M. I. 2019. Anterior capsulotomy for obsessive-compulsive disorder: A review of old and new literature. Journal of Neurosurgery 1-10https:// doi.org/10.3171/2019.4.JNS19275

44. Ravikumar, V.K., J.J. Parker, T.S. Hornbeck, V.E. Santini, K.B. Pauly, M. Wintermark, et al. 2017. Cost-effectiveness of focused ultrasound, radiosurgery, and DBS for essential tremor. Movement Disorders 32 (8): 1165-1173. https:// doi.org/10.1002/mds.26997.

45. Stroupe, K.T., B. Smith, F.M. Weaver, B. Gonzalez, Z. Huo, L. Cao, et al. 2019. Healthcare utilization and costs for patients with Parkinson's disease after deep brain stimulation. Movement Disorders Clinical Practice 6 (5): 369-378. https://doi.org/10.1002/mdc3.12765.

46. Kumar, K.K., M.T. Bhati, V.K. Ravikumar, P. Ghanouni, S.C. Stein, and C.H. Halpern. 2019. MR-guided focused ultrasound versus radiofrequency capsulotomy for treatmentrefractory obsessive-compulsive disorder: A cost-effectiveness threshold analysis. Frontiers in Neurosciences 13: 66. https://doi.org/10.3389/fnins.2019.00066.

47. Mendelsohn, D., N. Lipsman, A.M. Lozano, and T. T., M. Bernstein. 2013. The contemporary practice of psychiatric surgery: Results from a global survey of functional neurosurgeons. Stereotactic and Functional Neurosurgery 91: 306-313. https://doi.org/10.1159/000348323.

48. Cormier, J., C. Iorio-Morin, D. Mathieu, and S. Ducharme. 2019. Psychiatric neurosurgery: A survey on the perceptions of psychiatrists and residents. The Canadian Journal of Neurological Sciences 46: 303-310. https://doi.org/10. 1017/cjn.2019.5.

49. Cabrera, L.Y., M. Bittlinger, H. Lou, S. Müller, and J. Illes. 2018. Reader comments to media reports on psychiatric neurosurgery: Past history casts shadows on the future. Acta Neurochirurgica 160 (12): 2501-2507. https://doi. org/10.1007/s00701-018-3696-4.

50. Cabrera, L.Y., M. Bittlinger, H. Lou, S. Müller, and J. Illes. 2018. The re-emergence of psychiatric neurosurgery: Insights from a cross-national study of newspaper and magazine coverage. Acta Neurochirurgica 160 (3): 625-635. https://doi.org/10.1007/s00701-017-3428-1.

51. Cabrera, L.Y., M. Brandt, R. McKenzie, and R. Bluhm. 2018. Comparison of philosophical concerns between professionals and the public regarding two psychiatric treatments. AJOB Empirical Bioethics 9 (4): 252-266. https://doi.org/10.1080/23294515.2018.1512534.

52. Cabrera, L.Y., C. Courchesne, M. Bittlinger, S. Müller, R. Martínez-Álvarez, É. Racine, and J. Illes. 2020. Authentic self and last resort: International perceptions of psychiatric neurosurgery. Culture, Medicine and Psychiatry. https:// doi.org/10.1007/s11013-020-09679-1.

53. Hohagen, F., A. Wahl-Kordon, W. Lotz-Rambaldi, and C. Muche-Borowski. 2015. S3-Leitlinie Zwangsstörungen, AWMF-Registernummer 038/017. Berlin, Heidelberg: Springer.

54. Irle, E., C. Exner, K. Thielen, G. Weniger, and E. Rüther. 1998. Obsessive-compulsive disorder and ventromedial frontal lesions: Clinical and neuropsychological findings. American Journal of Psychiatry 155 (2): 255-263. https://doi.org/10.1176/ajp.155.2.255.

55. Rück, C, A. Karlsson, J. D. Steele, G. Edman, B. A. Meyerson, K. Ericson, et al. 2008. Capsulotomy for obsessive-compulsive disorder. Long-term follow-up of 25 patients. Archives of General Psychiatry 65(8): 914-921. https://doi.org/10.1001/ archpsyc.65.8.91.

56. Royal College of Psychiatrists. 2017. Statement on Neurosurgery for mental disorders (NMD), also known as psychiatric neurosurgery. Position statement CERT 05/17. February 2017. https://doi.org/https://www.rcpsych.ac.uk/docs/defau lt-source/about-us/who-we-are/ectcommittee-vns-dbsablative-neurosurgery-statement-feb17.pdf?sfvrsn=eba02 87a_2. Accessed 16 April 2020.

57. Wiesing, U., and A.J. Fallgatter. 2018. Rationality and freedom in medicine: The case of electroconvulsion therapy. Der Nervenarzt 89: 1248-1253. https://doi.org/10. 1007/s00115-018-0564-7.

58. Naesström, M., P. Blomstedt, M.I. Hariz, and O. Bodlund. 2017. Deep brain stimulation for obsessive-compulsive disorder: Knowledge and concerns among psychiatrists, psychotherapists and patients. Surgical Neurology International 8: 298. https://doi.org/10.4103/sni.sni_19_17.

59. Müller, S. 2014. Personality and autonomy in light of neuroscience. Habilitation, Charité - Universitätsmedizin Berlin, Berlin. https://doi.org/http://www.diss.fu-berlin. de/diss/receive/FUDISS_thesis_000000097489.

60. Müller, S., M. Bittlinger, and H. Walter. 2017. Threats to neurosurgical patients posed by the personal identity debate. Neuroethics 10: 299-310. https://doi.org/10. 1007/s12152-017-9304-0.

61. Gilbert, F., J.N.M. Viaña, and C. Ineichen. 2018. Deflating the "DBS causes personality changes" bubble. Neuroethics. https://doi.org/10.1007/s12152-018-9373-8.

62. Kubu, C.S., P.J. Ford, J.A. Wilt, A.R. Merner, M. Montpetite, J. Zeigler, and É. Racine. 2019. Pragmatism and 
the importance of interdisciplinary teams in investigating personality changes following DBS. Neuroethics 1-10. https://doi.org/10.1007/s12152-019-09418-3

63. Baertschi, B., S.A. Hurst, and A. Mauron. 2010. It's not who you are. AJOB Neuroscience 1 (3): 18-19. https:// doi.org/10.1080/21507740.2010.485269.

64. Müller, S., and M. Christen. 2011. Deep brain stimulation in Parkinsonian patients - ethical evaluation of stimulation-induced personality alterations. AJOB Neuroscience 2 (1): 3-13. https://doi.org/10.1080/21507740.2010. 533151.

65. Synofzik, M., and T.E. Schläpfer. 2008. Stimulating personality: Ethical criteria for deep brain stimulation in psychiatric patients and for enhancement purposes. Biotechnology Journal 3 (12): 1511-1520.

66. Müller, S., H. Walter, and M. Christen. 2014. When benefitting a patient increases the risk for harm for third persons - The case of treating pedophilic Parkinsonian patients with deep brain stimulation. International Journal of Law and Psychiatry 37: 295-303. https://doi.org/ 10.1016/j.ijlp.2013.11.015.

67. Beauchamp, T.L., and J.F. Childress. 2019. Principles of biomedical ethics, 8th ed. New York, Oxford: Oxford University Press.

68. Bouckoms, A.J. 1988. Ethics of psychosurgery. Acta Neurochirurgica Supplement (Wien) 44: 173-178.

69. Costa, P.T., and R.R. McCrae. 1992. Revised NEO Personality Inventory (NEO-PI-R) and NEO Five-Factor Inventory (NEO-FFI) professional manual. Odessa, FL: Psychological Assessment Resources Inc.

70. Paiva, R.R., M.C. Batistuzzo, N.C. McLaughlin, M.M. Canteras, M.E. de Mathis, G. Requena, et al. 2018. Personality measures after gamma ventral capsulotomy in intractable OCD. Progress in Neuro-Psychopharmacology \& Biological Psychiatry 81: 161-168. https://doi. org/10.1016/j.pnpbp.2017.10.023.

71. Hageman, S.B., G. van Rooijen, I.O. Bergfeld, F. Schirmbeck, P. de Koning, and P, P. R. Schuurman, and D. Denys. 2021. Deep brain stimulation versus ablative surgery for treatmentrefractory obsessive-compulsive disorder: A meta-analysis. Acta Psychiatrica Scandinavica. 143 (4): 307-318. https:// doi.org/10.1111/acps.13276.

72. Thomson, C.J., R.A. Segrave, É. Racine, N. Warren, D. Thyagarajan, and A. Carter. 2020. "He's back so I'm not alone": The impact of deep brain stimulation on personality, self, and relationships in Parkinson's disease. Qualitative Health Research 30 (14): 2217-2233. https://doi. org/10.1177/1049732320951144.

73. Christen, M., M. Bittlinger, H. Walter, P. Brugger, and S. Müller. 2012. Dealing with side effects of deep brain stimulation: Lessons learned from stimulating the STN. AJOB Neuroscience 3 (1): 37-43. https://doi.org/10. 1080/21507740.2011.635627.

74. Müller, S., R. Riedmüller, H. Walter, and M. Christen. 2015. An ethical evaluation of stereotactic neurosurgery for anorexia nervosa. AJOB Neuroscience 6 (4): 50-65. https://doi.org/10.1080/21507740.2015.1094536.

75. Wilt, J.A., A.R. Merner, J. Zeigler, M. Montpetite, and C.S. Kubu. 2021. Does personality change follow deep brain stimulation in Parkinson's disease patients?
Frontiers in Psychology 30 (12): 643277. https://doi.org/ 10.3389/fpsyg.2021.643277.

76. Zarzycki,M.Z., and I. Domitrz. 2020. Stimulation-induced side effects after deep brain stimulation - a systematic review. Acta Neuropsychiatrica 32 (2): 57-64. https://doi.org/10. 1017/neu.2019.35.

77. De Haan, S., E. Rietveld, M. Stokhof, and D. Denys. 2017. Becoming more oneself? Changes in personality following DBS treatment for psychiatric disorders: Experiences of OCD patients and general considerations. PLoS ONE 12 (4): e0175748. https://doi.org/10.1371/ journal.pone.0175748.

78. Raymaekers, S., Z. van Duppen, K. Demyttenaere, L. Luyten, L. Gabriels, B. Nuttin, and C. Bervoets. 2017. Deep brain stimulation and anterior capsulotomy: The question of autonomy. European Psychiatry 41 (S1): S323-S323. https://doi.org/10.1016/j.eurpsy.2017.02.249.

79. Klee, K. 2017. Lebenswert. Autobiographie von Katja Klee. ISBN: 978-3-00-055777-4.

80. Radano, Gerry. 2007. CONTAMINATED. My journey out of obsessive compulsive disorder. Scarsdale, New York: Bar-Le-Duc Books. ISBN: 978-0-9792288-0-3.

81. Mantione, M., M. Figee, and D. Denys. 2014. A case of musical preference for Johnny Cash following deep brain stimulation of the nucleus accumbens. Frontiers in Behavioral Neuroscience. 6 (8): 152. https://doi.org/10. 3389/fnbeh.2014.00152.

82. Ineichen, C., H. Baumann-Vogel, and M. Christen. 2016. Deep brain stimulation: In search of reliable instruments for assessing complex personality-related changes. Brain Sciences 6 (3): 40. https://doi.org/10.3390/brainsci6030040.

83. Lawrence, R.E., C.R. Kaufmann, R.B. DeSilva, and P.S. Appelbaum. 2018. Patients' beliefs about deep brain stimulation for treatment-resistant depression. AJOB Neuroscience 9 (4): 210-218. https://doi.org/10.1080/21507740. 2018.1553897.

84. Horng, S., and F. G. Miller. 2015. Ethics of sham surgery in clinical trials for neurologic disease. In Handbook of Neuroethics, ed. J. Clausen and N. Levy, Chapter 72, 1125-1137. Dordrecht: Springer Science + Business Media. https://doi. org/10.1007/978-94-007-4707-4_75.

85. Krauss, A. 2018. Why all randomised controlled trials produce biased results. Annals of Medicine 50 (4): 312322. https://doi.org/10.1080/07853890.2018.

86. Garnaat, S.L., B.D. Greenberg, N.J. Sibrava, W.K. Goodman, M.C. Mancebo, J.L. Eisen, and S.A. Rasmussen. 2014. Who qualifies for deep brain stimulation for OCD? Data from a naturalistic clinical sample. The Journal of Neuropsychiatry and Clinical Neurosciences 26 (1): 81-86. https://doi.org/10.1176/appi.neuropsych.12090226.

87. Burke, M.J., T.J. Kaptchuk, and A. Pascual-Leone. 2019. Challenges of differential placebo effects in contemporary medicine: The example of brain stimulation. Annals of Neurology 85 (1): 12-20. https://doi.org/10.1002/ana. 25387.

88. Guyatt, G., D. Sackett, D.W. Taylor, J. Chong, R. Roberts, and S. Pugsley. 1986. Determining optimal therapy - randomized trials in individual patients. New England Journal of Medicine 314 (14): 889-892. https://doi.org/10.1056/NEJM198604033141406. 
89. Senn, S. 2019. Sample size considerations for n-of-1 trials. Statistical Methods in Medical Research 28 (2): 372-383. https://doi.org/10.1177/0962280217726801.

90. World Medical Association. 2013. Declaration of Helsinki: Ethical Principles for Medical Research Involving Human Subjects. JAMA 310 (20): 2191-2194. https://doi.org/10.1001/jama.2013.281053.

91. Bundesinstitut für Arzneimittel und Medizinprodukte (BfArM) (Federal Institute for Drugs and Medical Devices). 2020. Glossar - Compassionate Use. https://doi.org/https:// www.bfarm.de/SharedDocs/Gloss arein traege/DE/C/ Compassionate_Use.html. Accessed 26 January 2020.

92. Fond, G., N. Hamdani, F. Kapczinski, W. Boukouaci, N. Drancourt, A. Dargel, et al. 2014. Effectiveness and tolerance of anti-inflammatory drugs' add-on therapy in major mental disorders: A systematic qualitative review. Acta Psychiatrica Scandinavica 129 (3): 163-179. https://doi. org/10.1111/acps.12211.

93. Marini, S., D. De Berardis, F. Vellante, R. Santacroce, L. Orsolini, A. Valchera, et al. 2016. Celecoxib adjunctive treatment to antipsychotics in schizophrenia: A review of randomized clinical add-on trials. Mediators of Inflammation 3476240. https://doi.org/10.1155/2016/3476240

94. Sommer, I.E., R. van Westrhenen, M.J. Begemann, L.D. de Witte, S. Leucht, and R.S. Kahn. 2014. Efficacy of anti-inflammatory agents to improve symptoms in patients with schizophrenia: An update. Schizophrenia Bulletin 40 (1): 181-191. https://doi.org/10.1093/schbul/ sbt139.

95. Bost, C., O. Pascual, and J. Honnorat. 2016. Autoimmune encephalitis in psychiatric institutions: Current perspectives. Neuropsychiatric Disease and Treatment 12: 27752787. https://doi.org/10.2147/NDT.S82380.

96. Steiner, J., H. Prüß, S. Köhler, T. Frodl, A. Hasan, and P. Falkai. 2018. Autoimmune encephalitis with psychosis: Warning signs, step-by-step diagnostics and treatment. The World Journal of Biological Psychiatry 4: 1-14. https://doi.org/10.1080/15622975.2018.1555376.

97. Breitschwerdt, E.B., R. Greenberg, R.G. Maggi, B.R. Mozayeni, A. Lewis, and J.M. Bradley. 2019. Bartonella henselae bloodstream infection in a boy with pediatric acute-onset neuropsychiatric syndrome. Journal of Central Nervous System Disease 11: 1-8. https://doi.org/10. 1177/1179573519832014.

98. Jackson, J.R., W.W.Eaton, N.G. Cascella, A. Fasano, and D.L. Kelly. 2012. Neurologic and psychiatric manifestations of celiac disease and gluten sensitivity. Psychiatric Quarterly 83: 91-102. https://doi.org/10.1007/s11126-011-9186-y.

99. Schläpfer, T.E., and J.J. Fins. 2010. Deep brain stimulation and the neuroethics of responsible publishing. When one is not enough. JAMA 303 (8): 775-776. https://doi. org/10.1001/jama.2010.140.

100. Chan, A.-W., A. Hróbjartsson, M.T. Haahr, P.C. Gøtzsche, and D.G. Altman. 2004. Empirical evidence for selective reporting of outcomes in randomized trials: Comparison of protocols to published articles. JAMA 291 (20): 24572465. https://doi.org/10.1001/jama.291.20.2457.

101. To, M.S., and A. Jukes. 2019. Reporting trends of p values in the neurosurgical literature. Journal of Neurosurgery 1: 1-9. https://doi.org/10.3171/2018.8.JNS172897.
102. DeVito, N. J., S. Bacon, and B. Goldacre. 2020. Compliance with legal requirement to report clinical trial results on ClinicalTrials.gov: a cohort study. Lancet S0140-6736(19): 33220-33229.

103. Wieschowski, S., N. Riedel, K. Wollmann, H. Kahrass, S. Müller-Ohlraun, C. Schürmann, et al. 2019. Result dissemination from clinical trials conducted at German university medical centers was delayed and incomplete. Journal of Clinical Epidemiology 115: 37-45. https://doi.org/10. 1016/j.jclinepi.2019.06.002.

104. Torres, C.V., N. Martínez, M. Ríos-Lago, M. Lara, J. Alvarez-Linera, J. Cabanyes, M.L. Dorado, W. Cabrera, G. Rey, and R. Martínez-Alvarez. 2021. Surgery and radiosurgery in autism: A retrospective study in 10 patients. Stereotactic and Functional Neurosurgery 2: 1-10. https://doi.org/10.1159/000516963.

105. Csigó, K., A. Harsányi, G. Demeter, C. Rajkai, A. Németh, and M. Racsmány. 2010. Long-term follow-up of patients with obsessive-compulsive disorder treated by anterior capsulotomy: A neuropsychological study. Journal of Affective Disorders 126: 198-205. https://doi.org/10.1016/j.jad. 2010.02.127.

106. Steele, J.D., D. Christmas, M.S. Eljamel, and K. Matthews. 2008. Anterior cingulotomy for major depression: Clinical outcome and relationship to lesion characteristics. Biological Psychiatry 63: 670-677. https://doi.org/10.1016/j.biopsych. 2007.07.019.

107. Ebell, M.H., J. Siwek, B.D. Weiss, S.H. Woolf, J. Susman, B. Ewigman, and M. Bowman. 2004. Strength of recommendation taxonomy (SORT): A patient-centered approach to grading evidence in the medical literature. The Journal of the American Board of Family Practice. 17 (1): 59-67. https://doi.org/10.3122/jabfm.17.1.59.

108. Miguel, E.C., A.C. Lopes, N.C.R. McLaughlin, G. Norén, A.F. Gentil, C. Hamani, et al. 2019. Evolution of gamma knife capsulotomy for intractable obsessive-compulsive disorder. Molecular Psychiatry 24 (2): 218-240. https:// doi.org/10.1038/s41380-018-0054-0.

109. Rasmussen, S., G. Noren, B.D. Greenberg, R. Marsland, N.C. McLaughlin, P.J. Malloy, et al. 2017. Gamma ventral capsulotomy in intractable obsessive-compulsive disorder. Biological Psychiatry 84 (5): 355-364. https://doi. org/10.1016/j.biopsych.2017.11.034.

110. Gupta, A., M.J. Shepard, Z. Xu, T. Maiti, N. MartinezMoreno, J. Silverman, et al. 2019. An international radiosurgery research foundation multicenter retrospective study of gamma ventral capsulotomy for obsessive compulsive disorder. Neurosurgery 85 (6): 808-816. https:// doi.org/10.1093/neuros/nyy536.

111. Park, S.C., J.K. Lee, C.H. Kim, J.P. Hong, and D.H. Lee. 2017. Gamma-knife subcaudate tractotomy for treatmentresistant depression and target characteristics: A case report and review. Acta Neurochirurgica 159: 113-120. https://doi.org/10.1007/s00701-016-3001-3.

112. Lopes, A. C., B. D. Greenberg, M. M. Canteras, M. C. Batistuzzo, M. Q. Hoexter, A. F. Gentil et al. 2014. Gamma ventral capsulotomy for obsessive-compulsive disorder - a randomized clinical trial. JAMA Psychiatry 71(9): 1066-1076. https://doi.org/10.1001/jamapsychiatry. 2014.1193 (Retracted and replaced on October 28, 2015. Last corrected on January 6, 2016). 
113. Davidson, B., C. Hamani, Y. Meng, A. Baskaran, S. Sharma, A. Abrahao, et al. 2020. Examining cognitive change in magnetic resonance-guided focused ultrasound capsulotomy for psychiatric illness. Translational Psychiatry. 10 (1): 397. https://doi.org/10.1038/ s41398-020-01072-1.

114. Davidson, B., C. Hamani, J.S. Rabin, M. Goubran, Y. Meng, Y. Huang, et al. 2020. Magnetic resonance-guided focused ultrasound capsulotomy for refractory obsessive compulsive disorder and major depressive disorder: Clinical and imaging results from two phase I trials. Molecular Psychiatry 25 (9): 1946-1957. https://doi.org/ 10.1038/s41380-020-0737-1.

115. Na, Y. C., H. H. Jung, and J. W. Chang. 2015. Focused ultrasound for the treatment of obsessive-compulsive disorder. In Neurosurgical treatments for psychiatric disorders, ed. B. Sun and A. De Salles, 125-141. Dordrecht: Springer. https://doi.org/10.1007/978-94-017-9576-0_12.

116. Chang, J.-G., H.H. Jung, S.J. Kim, W.S. Chang, Y.J. Na, C.-H. Kim, and J.W. Chang. 2020. Bilateral thermal capsulotomy with magnetic resonance-guided focused ultrasound for patients with treatment-resistant depression: A proof-of-concept study. Bipolar Disorders 22 (7): 771774. https://doi.org/10.1111/bdi.12964.

117. Elias, W.J., N. Lipsman, W.G. Ondo, P. Ghanouni, Y.G. Kim, W. Lee, et al. 2016. A randomized trial of focused ultrasound thalamotomy for essential tremor. New England Journal of Medicine 375: 730-739. https://doi.org/ 10.1056/NEJMoa1600159.

118. Christen, M., and S. Müller. 2018. The ethics of expanding applications of deep brain stimulation. In Routledge Handbook of Neuroethics, ed. L.S. Johnson and K. Rommelfanger, 51-65. New York: Routledge.

119. Bergfeld, I.O., M. Mantione, M.L.C. Hoogendoorn, H.G. Ruhé, P. Notten, J. van Laarhoven, et al. 2016. Deep brain stimulation of the ventral anterior limb of the internal capsule for treatment-resistant depression. A randomized clinical trial. JAMA Psychiatry 73 (5): 456-464. https://doi.org/10.1001/jamapsychiatry.2016.0152.

120. Vicheva, P., M. Butler, and P. Shotbolt. 2020. Deep brain stimulation for obsessive-compulsive disorder: A systematic review of randomized controlled trials. Neuroscience \& Biobehavioral Reviews 109: 129-138. https://doi.org/ 10.1016/j.neubiorev.2020.01.007.

121. Kohl, S., D.M. Schönherr, J. Luigjes, D. Denys, U.J. Müller, D. Lenartz, et al. 2014. Deep brain stimulation for treatment-refractory obsessive-compulsive disorder: A systematic review. BMC Psychiatry 14: 214. https:// doi.org/10.1186/s12888-014-0214-y.

122. Kisely, S., K. Hall, D. Siskind, J. Frater, S. Olson, and D. Crompton. 2014. Deep brain stimulation for obsessivecompulsive disorder: A systematic review and meta-analysis. Psychological Medicine 44 (16): 3533-3542. https:// doi.org/10.1017/S0033291714000981.

123. Goodman, W.K., E.A. Storch, J.F. Cohn, and S.A. Sheth. 2010. Deep brain stimulation for intractable obsessivecompulsive disorder: Pilot study using a blinded, staggeredonset design. Biological Psychiatry 67: 535-542. https:// doi.org/10.1176/appi.ajp.2020.20010037.

124. Schruers, K., S. Baldi, T. van den Heuvel, L. Goossens, L. Luyten, A.F.G. Leentjens, et al. 2019. The effects of deep-brain non-stimulation in severe obsessive-compulsive disorder: An individual patient data meta-analysis. Translational Psychiatry 9 (1): 183. https://doi.org/10. 1038/s41398-019-0522-6.

125. Kisely, S., A. Li, N. Warren, and D. Siskind. 2018. A systematic review and meta-analysis of deep brain stimulation for depression. Depression and Anxiety 35: 468480. https://doi.org/10.1002/da.22746.

126. Zhou, C., H. Zhang, Y. Qin, T. Tian, B. Xu, J. Chen, et al. 2018. A systematic review and meta-analysis of deep brain stimulation in treatment-resistant depression. Progress in Neuro-Psychopharmacology \& Biological Psychiatry 82: 224-232. https://doi.org/10.1016/j.pnpbp. 2017.11.012.

127. Dougherty, D.D., A.R. Rezai, L.L. Carpenter, R.H. Howland, M.T. Bhati, J.P. O'Reardon, et al. 2015. A randomized shamcontrolled trial of deep brain stimulation of the ventral capsule/ventral striatum for chronic treatment-resistant depression. Biological Psychiatry 78: 240-248. https://doi.org/10. 1016/j.biopsych.2014.11.023.

128. Holtzheimer, P.E., M.M. Husain, S.H. Lisanby, S.F. Taylor, L.A. Whitworth, S. McClintock, et al. 2017. Subcallosal cingulate deep brain stimulation for treatment-resistant depression: A multisite, randomised, sham-controlled trial. Lancet Psychiatry 4: 839-849. https://doi.org/10.1016/ S2215-0366(17)30371-1.

129. Coenen, V.A., B.H. Bewernick, S. Kayser, H. Kilian, J. Boström, S. Greschus, et al. 2019. Superolateral medial forebrain bundle deep brain stimulation in major depression: A gateway trial. Neuropsychopharmacology 44 (7): 1224-1232. https://doi.org/10.1038/s41386-019-0369-9.

130. Laxton, A.W., D.F. Tang-Wai, M.P. McAndrews, D. Zumsteg, R. Wennberg, R. Keren, et al. 2010. A phase I trial of deep brain stimulation of memory circuits in Alzheimer's disease. Annals of Neurology 68 (4): 521-534. https://doi.org/10.1002/ana.22089.

131. Kuhn, J., K. Hardenacke, D. Lenartz, T. Gruendler, M. Ullsperger, C. Bartsch, et al. 2015. Deep brain stimulation of the nucleus basalis of Meynert in Alzheimer's dementia. Molecular Psychiatry 20 (3): 353-360. https:// doi.org/10.1038/mp.2014.32.

132. Scharre, D., E. Weichart, D. Nielson, J. Zhang, P. Agrawal, P. Sederberg, et al. 2018. Deep brain stimulation of frontal lobe networks to treat Alzheimer's disease. Journal of Alzheimers' Disease 62 (2): 621-633. https:// doi.org/10.3233/JAD-170082.

133. Lozano, A.M., L. Fosdick, M.M. Chakravarty, J.M. Leoutsakos, C. Munro, E. Oh, et al. 2016. A phase II study of fornix deep brain stimulation in mild Alzheimer's disease. Journal of Alzheimers' Disease 54 (2): 777-787. https://doi.org/10.3233/JAD-160017.

134. Bittlinger, M., and S. Müller. 2018. Opening the debate on deep brain stimulation for Alzheimer disease - a critical evaluation of rationale, shortcomings, and ethical justification. BMC Medical Ethics 19 (41): 1-23. https://doi. org/10.1186/s12910-018-0275-4.

135. Fong, T. G., R. N. Jones, E. R. Marcantonio, D. Tommet, A. L. Gross, D. Habtemariam, et al. 2012. Adverse outcomes after hospitalization and delirium in persons with Alzheimer's diseases. Annals of Internal Medicine 19;156(12): 
848-856, W296. https://doi.org/10.7326/0003-4819-15612-201206190-00005.

136. Chou, R.C., M. Kane, S. Ghimire, S. Gautam, and J. Gui. 2016. Treatment for rheumatoid arthritis and risk of Alzheimer's disease: A nested case-control analysis. CNS Drugs 30 (11): 1111-1120. https://doi.org/10.1007/ s40263-016-0374-z.

137. Schneider, L. 2020. A resurrection of aducanumab for Alzheimer's disease. Lancet Neurology 36 (50): 1254912558. https://doi.org/10.1016/S1474-4422(19)30480-6.

138. Cavuoto, J. Depressing innovation. Neurotech Business Report (2013). https://doi.org/http://www.neuro techreports.com/pages/publishersletterDec13.html. Accessed 7 April 2020.

139. Schläpfer, T.E. 2015. Deep brain stimulation for major depression - steps on a long and winding road. Commentary. Biological Psychiatry 78: 218-219.

140. Crowell, A.L., P. Riva-Posse, P.E. Holtzheimer, S.J. Garlow, M.E. Kelley, R.E. Gross, L. Denison, S. Quinn, and H.S. Mayberg. 2019. Long-term outcomes of subcallosal cingulate deep brain stimulation for treatment-resistant depression. The American Journal of Psychiatry 176 (11): 949-956. https://doi.org/10.1176/appi.ajp.2019.18121427.

141. Fins, J.J., C.S. Kubu, H.S. Mayberg, R. Merkel, B. Nuttin, and T.E. Schläpfer. 2017. Being open minded about neuromodulation trials: Finding success in our "failures." Brain
Stimulation 10: 181-186. https://doi.org/10.1016/j.brs. 2016.12.012.

142. Appelbaum, P.S., M. Anatchkova, K. Albert, L.B. Dunn, and C.W. Lidz. 2012. Therapeutic misconception in research subjects: Development and validation of a measure. Clinical Trials (London, England). 9 (6): 748-761. https://doi.org/10.1177/1740774512456455.

143. Hendriks, S., C. Grady, K.M. Ramos, W. Chiong, J.J. Fins, P. Ford, et al. 2019. Ethical challenges of risk, informed consent, and posttrial responsibilities in human research with neural devices: A review. JAMA Neurology. https://doi.org/10.1001/jamaneurol.2019.3523.

144. Winter, L., A. Saryyeva, K. Schwabe, H.E. Heissler, J. Runge, M. Alam, I. Heitland, K.G. Kahl, and J.K. Krauss. 2021. Long-term deep brain stimulation in treatment-resistant obsessive-compulsive disorder: Outcome and quality of life at four to eight years follow-up. Neuromodulation 24 (2): 324-330. https://doi.org/10.1111/ner. 13232.

Publisher's Note Springer Nature remains neutral with regard to jurisdictional claims in published maps and institutional affiliations. 